\title{
How the Body Talks to the Brain; Peripheral Mediators of Physical Activity-Induced Proliferation in the Adult Hippocampus
}

\author{
Simone Bolijn* and Paul J. Lucassen* \\ Centre for Neuroscience, Swammerdam Institute of Life Sciences, University of Amsterdam, \\ Amsterdam, The Netherlands
}

\begin{abstract}
In the hippocampal dentate gyrus, stem cells maintain the capacity to produce new neurons into adulthood. These adult-generated neurons become fully functional and are incorporated into the existing hippocampal circuit. The process of adult neurogenesis contributes to hippocampal functioning and is influenced by various environmental, hormonal and disease-related factors.

One of the most potent stimuli of neurogenesis is physical activity (PA). While the bodily and peripheral changes of PA are well known, e.g. in relation to diet or cardiovascular conditions, little is known about which of these also exert central effects on the brain. Here, we discuss PA-induced changes in peripheral mediators that can modify hippocampal proliferation, and address changes with age, sex or PA duration/intensity.

Of the many peripheral factors known to be triggered by PA, serotonin, FGF-2, IGF-1, VEGF, $\beta$-endorphin and adiponectin are best known for their stimulatory effects on hippocampal proliferation. Interestingly, while age negatively affects hippocampal proliferation per se, also the PA-induced response to most of these peripheral mediators is reduced and particularly the response to IGF-1 and NPY strongly declines with age. Sex differences per se have generally little effects on PA-induced neurogenesis.

Compared to short term exercise, long term PA may negatively affect proliferation, due to a parallel decline in FGF-2 and the $\beta$-endorphin receptor, and an activation of the stress system particularly during conditions of prolonged exercise but this depends on other variables as well and remains a matter of discussion. Taken together, of many possible mediators, serotonin, FGF-2, IGF-1, VEGF, $\beta$-endorphin and adiponectin are the ones that most strongly contribute to the central effects of PA on the hippocampus. For a subgroup of these factors, brain sensitivity and responsivity is reduced with age.
\end{abstract}

Keywords: Neurogenesis, hippocampus, physical exercise, FGF-2, IGF-1, VEGF, $\beta$-endorphin, serotonin

\section{INTRODUCTION}

During early embryology, new neurons are formed in massive numbers. In later stages of brain development, the extent of neurogenesis decreases strongly and the adult brain is generally considered incapable of producing new neurons, except for the subventricular zone and the hippocampal dentate gyrus. Here, stem

${ }^{*}$ Correspondence to: Paul J. Lucassen and Simone Bolijn, Centre for Neuroscience, Swammerdam Institute of Life Sciences, University of Amsterdam, P.O. box 94214, 1090 GE Amsterdam, The Netherlands. E-mails: simonebolijn02@gmail.com (Simone Bolijn), p.j.lucassen@uva.nl (Paul J. Lucassen). cells continue to proliferate, differentiate and, after a selection phase during which many undergo apoptotic cell death [1], eventually develop into fully functional neurons that integrate in, and contribute to the mature trisynaptic network of the adult hippocampus [2-8]. These newborn neurons receive synaptic input and survive for prolonged periods of time, during which they continue to form dendrites and spines and receive relevant inputs [2, 3, 7-10].

By now, numerous behavioral and physiological studies have established a functional role for these adult generated cells $[3,4,11-14]$ and their turnover $[15,16]$, in various behavioral tasks and paradigms, including 
e.g. spatial learning, fear memory and pattern separation. In addition, animal studies have suggested the involvement of hippocampal neurogenesis in specific aspects of brain disorders like depression and stress regulation [3, 17-20], anxiety [18, 19], aging [21, 22], and cognitive decline $[3,4,14,21]$. Hence, approaches aimed towards a better understanding of the modulation and control of neurogenesis, e.g. using peripheral or environmental factors, could have important clinical benefits [23, 24].

The process of neurogenesis, i.e. the stem cell proliferation, apoptotic selection, survival and neuronal differentiation is regulated by many factors including specific genes, growth factors, hormones, behavior and environment [3, 5, 9, 17, 20, 25-32]. Of these, enriched environmental housing (EE) and stress [33] are well known to stimulate and inhibit (stages of) neurogenesis, respectively. Physical exercise also represents a major positive regulator of adult neurogenesis even in aged animals [12, 20, 22, 25, 26, 29, 34-40]. Physical activity (PA), commonly tested in rodents by placing a running wheel in their cage, is mostly studied for several days or one month but even after already 24 hours of wheel exposure, an increase in neurogenesis can be detected [41] that may be paralleld by rapid changes in angiogenesis [42]. Animals show an increase in neurogenesis upon PA, and in parallel, PA often improves cognitive measures as well [4, 11-14, 34-36, 43]. In addition, human imaging studies have shown positive effects of PA on both hippocampal volume [34, 44, $45]$, considered as indirect measure of neurogenesis $[22,34]$, as well as on cognitive functions including memory [14, 23, 24, 34, 44, 46] suggesting mental and physical activity may be beneficial for human brain health [14, 45, 47-51].

Running, or physical exercise per se, is a relatively simple and naturalistic form of activity that can generally be incorporated in a busy daily schedule. However, for many, doing exercise or engaging in sports-related activities is not possible, either because of logistic, practical or psychological obstacles, or because of physiological, physical or psychiatric limitations, that e.g. accompany old age, or in handicapped, disabled or diseased subjects. These groups might benefit from treatments mimicking the effects of running on the brain [51], but would require the identification of the bioactive compounds that actually mediate the beneficial effects of exercise on the brain. For a number of compounds we know their involvement in PAinduced neurogenesis, undoubtedly many more will be discovered in the future. Furthermore, it remains poorly understood how exactly exercise, training of peripheral muscles and the discovered mediators can affect stem cell proliferation and neurogenesis inside the brain.

Therefore, we here discuss how the 'body talks to the brain' and review some of the underlying mechanisms and mediators of PA-induced hippocampal plasticity. After a brief summary of adult neurogenesis, we address some general physiological changes occurring in the periphery in response to PA before focusing on some of the main bioactive compounds that are produced after aerobic exercise and induce proliferation in the hippocampus. We further discuss some PA-induced mediators that affect proliferation also indirectly, and conclude with the effects of age, sex and PA duration/intensity on PA-induced hippocampal proliferation.

\section{ADULT HIPPOCAMPAL PROLIFERATION AND NEUROGENESIS}

The hippocampus is a key brain region involved in learning and memory amongst others. It receives information from numerous brain areas, including the amygdala, olfactory bulb, hypothalamus and medial septum [6] from which projections arrive through the fornix or perforant pathway onto the pyramidal cells of the Cornu Ammonis 3 (CA3) and granule cells in the hippocampal dentate gyrus (DG) [52]. Within the DG, the subgranular zone (SGZ) holds neuronal stem cells (NSCs) that can undergo proliferation. A substantial percentage undergoes apoptotic cell death $[1,18]$ and around 10-12 days after proliferation, a considerable proportion of NSCs survives and migrates into the granular cell layer (GCL) where some of them subsequently differentiate into a neuronal phenotype that form synapses on the CA3 and hilar neurons whereas others undergo apoptosis (Fig. 1) [1, 3, 5, 17].

In this period, experience modifies the survival and fate decisions of the adult-generated cells, e.g. through the expression of activity-dependent immediate early genes and various growth factors [3, 5, 9, 32, 52]. The newborn neurons that survive after 4 to 8 weeks eventually have neuronal physiological properties that are largely similar to mature, pre-existing neurons [2], except that at a younger age, the adult-generated ones are easier to excite and e.g. have different thresholds for long term potentiation induction relative to adult neurons [7, 10, 53]. Eventually, the surviving NSCs develop into fully functional neurons that are incorporated within, and contribute to the existing tri-synaptic hippocampal network [6]. 


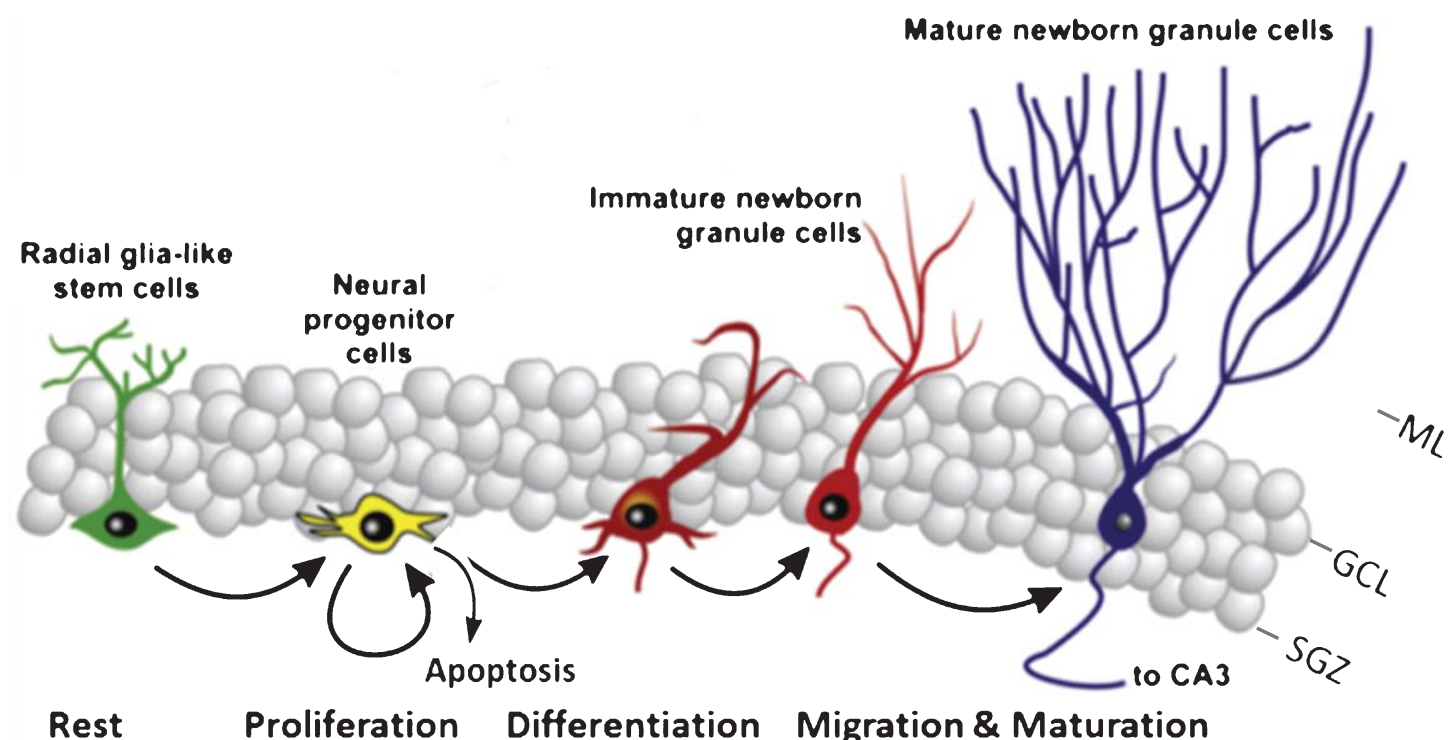

Fig. 1. Schematic diagram illustrating the different phases of neurogenesis in the dentate gyrus. Indicated in the bar below is which specific phases of neurogenesis are generally modified by exercise and enriched environmental housing. Note that there is some overlap and that a proportion of the adult-generated cells undergo apoptosis during the earliest phases of neurogenesis. $\mathrm{ML}=$ molecular layer; GCL $=$ granular cell layer; SGZ = subgranular zone; CA3 = Cornu Ammonis 3. (Adapted from Lucassen et al Eur NeuroPsychoPharm 2010) [17].

Environmental stimulation can promote neurogenesis in rodents and different stimuli often stimulate different stages of neurogenesis to a different extent (Fig. 1) [25, 30, 39, 48, 54-56]. As a running wheel is generally one of the components that make up an enriched environment for mice, it is important to note that this contributes significantly to the effects on neurogenesis $[30,37,50]$. Both in young and old individuals, PA is a strong stimulator of functional as well as structural brain plasticity $[26,29,35,36,38,39$, $43,57,58]$. The latter mainly includes the proliferation phase, while later stages, such as the survival of the newborn cells and their neuronal differentiation, appear to be stronger stimulated by environmental enrichment (EE). Regarding the possible influence of enrichment in an otherwise boring cage, there is some debate as to whether just the presence of a running wheel alone already changes the environment and/or motivation and aspects of energy metabolism of the animals [28, 59] that are known to be interested in such wheels per se [60] and in some studies a third group is e.g. added with a locked wheel present in the cage to control for possible effects of enrichment per se. Bednarczyk and colleagues found that the presence of a running wheel alone was already sufficient and equally potent to increase proliferation [29]. Moreover, running increased the amount of surviving neurons whereas this did not occur in the cage with the locked wheel. However, Grégoire et al., used a variety of proliferation, not neurogenesis, markers and found that a running disk, not wheel, significantly increased proliferation compared to a locked disk [20] and hence, the type of wheel and cage conditions may influence the engagement of the animals, and thus the effects on neurogenesis as well.

While running is a major neurogenic stimulus often present in an enriched environment $[20,26,37,39$, 54, 55, 61], EE alone also stimulates cell survival through at least two key elements; cognitive challenges and stress reduction [20, 50, 54, 61, 62]. Moreover, the combination of PA and cognitive challenges increases the effect of either stimulus alone [25, 48-50], which is proposed to have had evolutionary advantages [61]. PA further modifies the expression of several enzymes, growth factors and transcription factors that are involved in the stimulation of NSCs [31, 63-74], some of them originating from the periphery, as discussed below. 


\section{EFFECTS OF PA ON PERIPHERAL METABOLIC AND HORMONAL MARKERS}

During bodily movements and physical exercise, muscles contract and relax in a well-coordinated manner. Dependent on the oxygenation, their level of activation and intensity of the exercise, active muscle produce several bioactive compounds that generally help to adapt and promote muscle repair or growth, or vascular function and/or metabolism. Other organs such the kidneys and liver respond to different effects of PA, such as sweat production and a drop in glucose respectively. This enables the body to, on the one hand, adapt to exercise by secreting hormones released e.g. by endocrine organs to recover from, and replenish the initial energy depletion and prevent later exhaustion. On the other hand, it facilitates muscle remodeling and growth after training by changes in protein metabolism. In addition, angiogenesis is a prominent consequence of muscle activity and exercise.

Besides the effects these locally produced factors exert on the peripheral parts of the body, many of these factors are secreted and often reach the blood- stream from where they can affect the brain as well (Table 1; Fig. 2). In addition to the compounds entering the brain through the blood brain barrier (BBB), the brain also responds to PA by locally regulating some compounds. For one the brain produces proteins to reduce neuronal excitability and cope with the drop in glucose following PA. Furthermore, several growth factors are altered by PA to enable the brain to 'learn from experience'. These growth factors or neurotrophins are important for hippocampal neurons and exert a plethora of effects, amongst others neuronal growth, proliferation, differentiation and maturation in the hippocampus. The mechanisms behind the PA-induced increase of these factors in the hippocampus likely involves peripheral signals, but also neuronal component could be at play. For instance, the fornix and the medial perforant pathway [75, 76] are known to increase theta frequency signals to the hippocampus during conditions of exercise. Theta waves have been proposed as a cue for arousal, orientation and attention to the environment and are involved in memory consolidation processes [75, 77]. Increased activity of the GABAergic, glutamatergic

Table 1

Physiological changes during exercise

\begin{tabular}{|c|c|c|c|}
\hline Hormone/factor/neurotransmitter & Main function in exercise & Produced in & Reference number \\
\hline Insulin $\&$ insulin-like growth factor 1 & Increase protein synthesis & Liver $(\mathrm{P})$ & {$[78,79]$} \\
\hline Adiponectin & Increase glucose uptake & Fat cells $(\mathrm{P})$ & {$[80,81]$} \\
\hline$\downarrow$ Leptin & $\begin{array}{l}\text { Shifts metabolism from glucose } \\
\text { to fat \& decreases food intake }\end{array}$ & Fat cells $(\mathrm{P})$ & {$[81,82]$} \\
\hline Angiotensin II & Increase body fluid & Kidney $(\mathrm{P})$ & {$[78,83]$} \\
\hline Glucocorticoids & Initiate stress response & Adrenal cortex $(\mathrm{P})$ & {$[82]$} \\
\hline (Nor)adrenaline ((nor)epinephrine) & $\begin{array}{l}\text { Increase activation of the } \\
\text { sympathetic system }\end{array}$ & Adrenal cortex $(\mathrm{P})$ & {$[82]$} \\
\hline Reactive oxygen species & Stimulate AMP-kinase & Muscles (P) & [84] \\
\hline AMP-kinase & Increase available energy & Muscles (P) & {$[84-86]$} \\
\hline $\begin{array}{l}\text { Peroxisome proliferator- } \\
\text { activated receptor (PPAR) }\end{array}$ & $\begin{array}{l}\text { Transcription factor } \\
\text { regulating metabolism }\end{array}$ & Muscles (P) & [87] \\
\hline PPAR gamma co-activator $1 \alpha$ & Muscle plasticity & Muscles (P) & [88] \\
\hline$-/ \uparrow$ Ciliary neurotrophic factor & $\begin{array}{l}\text { Promote survival of } \\
\text { neurons in skeletal muscle }\end{array}$ & Muscles (P) & [89] \\
\hline Vascular endothelial growth factor & Stimulate angiogenesis & Muscles (P) and more (P \& C) & {$[90,91]$} \\
\hline$\downarrow$ Cytokines (proinflammatory) & Regulate immune response & Produced peripherally $(\mathrm{P})$ & [12] \\
\hline Serotonin & Regulate mood, appetite and sleep & Hippocampus (C) & [92] \\
\hline Acetylcholine, glutamate \& GABA & Convey signals & Hippocampus (C) & {$[93,94]$} \\
\hline Brain derived neurotrophic factor & Neuroprotective factor \& CNS plasticity & Hippocampus (C) & [12] \\
\hline$-/ \downarrow$ Neurotrophin-3 & $\begin{array}{l}\text { Regenerate of nerves, stimulate } \\
\text { and control neurogenesis }\end{array}$ & Hippocampus (C) & [37] \\
\hline Nerve growth factor & Increase of neuronal growth & Hippocampus (C) & [95] \\
\hline Fibroblast growth factor 2 & Nerve growth \& CNS plasticity & Hippocampus (C) & [96] \\
\hline Neuropeptide Y & $\begin{array}{l}\text { Regulate feeding behavior, energy } \\
\text { balance and pituitary secretion }\end{array}$ & Hippocampus (C) & [97] \\
\hline Vasoactive intestinal peptide & $\begin{array}{l}\text { Regulate cardiovascular } \\
\text { rhythm \& CNS plasticity }\end{array}$ & Hippocampus (C) & [98] \\
\hline$\beta$-endorphin & Decrease pain & Pituitary gland $(\mathrm{C})$ & [99] \\
\hline
\end{tabular}

Most hormones, factors and neurotransmitters are increased in response to physical activity, except for leptin, specific cytokines and neurotrophic3. All factors produced in the periphery are able to cross the blood brain barrier. $P=$ mainly peripheral production; $\mathrm{C}=$ mainly central production. 


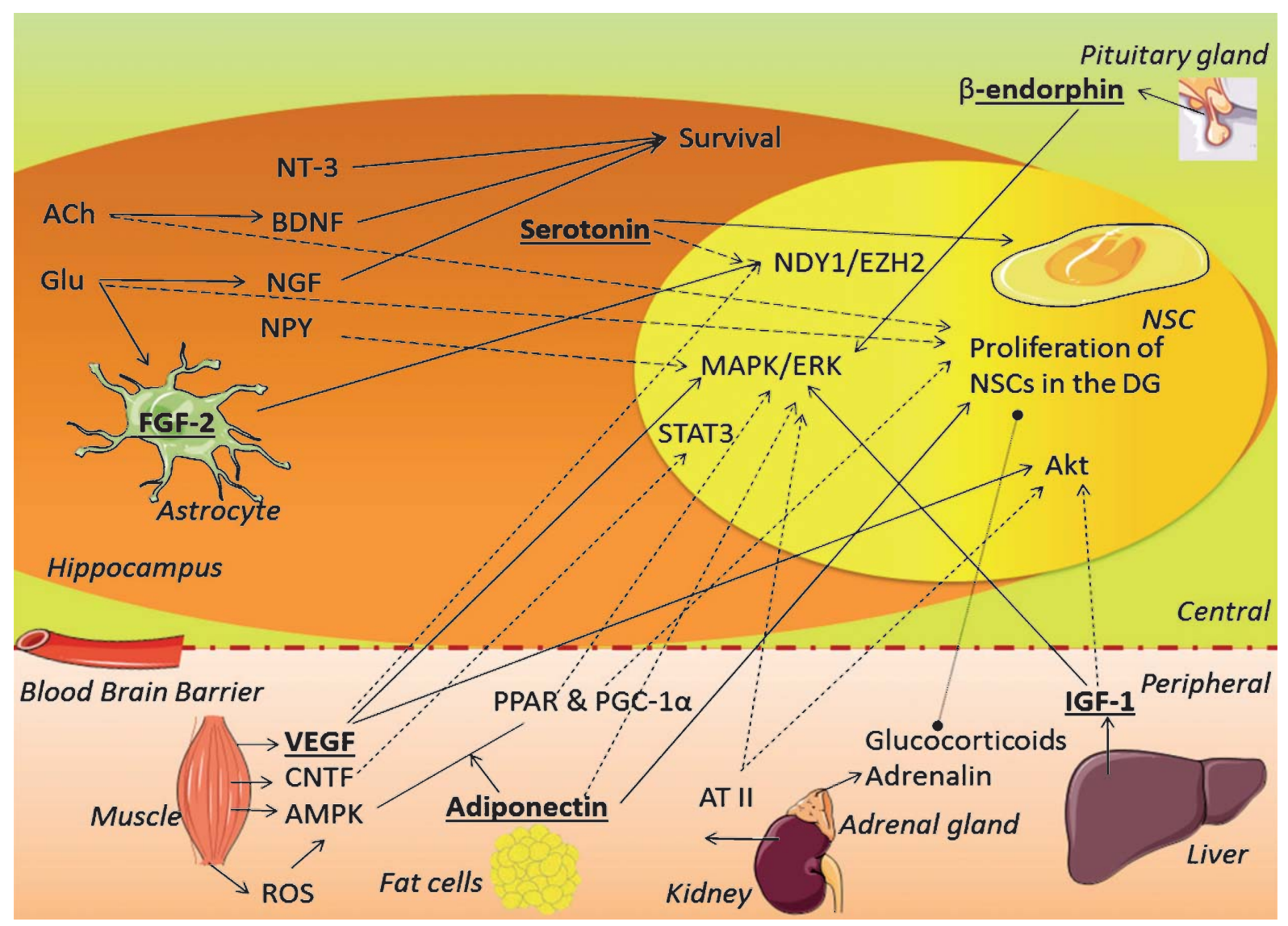

Fig. 2. Schematic overview of the role candidate factors might play on proliferation. The factors discussed in the text are placed here together in one schematic overview to illustrate their interconnections. Straight arrows refer to production, activation or induction. Dashed arrows refer to possible connections, and a dashed line refers to a direct effect by systemic factors. Factors in bold and underlined indicate an apparent role in PA-induced proliferation. $\mathrm{ACh}=$ acetylcholine, $\mathrm{AMPK}=\mathrm{AMP}-\mathrm{kinase} ; \mathrm{ATII}=$ angiotensin $\mathrm{II} ; \mathrm{BDNF}=$ brain derived neurotrophic factor; $\mathrm{CNTF}=$ ciliary neurotrophic factor; FGF-2 = fibroblast growth factor 2; Glu = glutamate; IGF-1 = insulin-like growth factor 1 ; NGF = neuronal growth factor; NPY = neuropeptide Y; NSC = neuronal stem cell; NT-3 = neurotrophin- $3 ;($ ROS $)=$ reactive oxygen species; PGC-1 $\alpha=$ PPAR gamma co-activator $1 \alpha$; PPARR = peroxisome proliferator-activated receptor; VEGF= vascular endothelial growth factor; VIP= vasoactive intestinal peptide.

and cholinergic afferents elevates extracellular lactate levels [100] as well as the levels of specific neurotransmitters $[93,94]$ in the hippocampus, which e.g. for acetylcholine, can in turn induce production of growth factors [93, 101]. As an example, Nochi and colleagues found that theta-burst stimulation of the perforant pathway stimulated hippocampal proliferation through an increase in glutamate levels in animals. In vitro follow up showed this was both dependent on the metabolic glutamate receptor 5, present on NSCs, as well as on vascular endothelial growth factor (VEGF) [102]. Other studies also suggest a cholinergic dependency as basal [103] and PA-induced [94] levels of proliferation were abrogated by septal-to-hippocampal lesioning of the cholinergic afferents. Furthermore, acetylcholine can activate proliferation through activa- tion of metabolic acetylcholine receptor M1 on NSCs in vitro [94]. Hence, proliferation can be induced by modulating main neurotransmitter inputs to the hippocampus [104].

For a factor to stimulate proliferation, it needs to stimulate the NSCs in the DG. Important intracellular pathways for this are the mitogen-activated protein kinase (MAPKs), extracellular-signal-regulated kinases (ERKs) [13, 27, 105, 106] and Akt pathways [105, 107]. In addition, factors involved in gene transcription, like the signal transducer and activator of transcription 3 (STAT3) protein [108, 109] and the enzyme histone-lysine N-methyltransferase EZH2 [110], can induce proliferation of NSCs as well. The details of these pathways fall beyond the scope of this review and will not be further discussed. 
While the type and magnitude of such a peripheral response is influenced by multiple factors, including the interval and period of rest between different trainings, and the intensity, duration and type of physical exercise, many of the changes mentioned in Table 1 occur during all forms of exercise [78]. Note that although an extensive list exists of PA-induced bioactive compounds, not all are well understood and even today more factors continue to be discovered.

In summary, PA, induces a variety of hormonal and physiological responses, both in the periphery and within the central nervous system (CNS). Most peripheral changes do not remain confined to the peripheral system as many of these factors are, in variable degrees, able to cross the BBB. This enables these factors to influence brain function and also hippocampal proliferation.

\section{CANDIDATE CENTRAL AND PERIPHERAL FACTORS INDUCING PROLIFERATION IN THE BRAIN}

\section{a) Growth factors/neurotrophins}

Growth factors or neurotrophins are well known for their promotion of (nerve) cell growth and their role in neurogenesis regulation during development and adulthood [31, 64]. The growth factors important during development often have very similar functions in adult conditions and we therefore limit ourselves to the main growth factors relevant for adult neurogenesis. We will discuss here; brain-derived neurotrophic factor (BDNF), neurotrophin-3 (NT-3), nerve Growth Factor (NGF), fibroblast growth factor (FGF-2), ciliary neurotrophic factor (CNTF), insulin-like growth factor (IGF-1) and vascular endothelial growth factor (VEGF) (see also Table 2).

\section{i. $B D N F$}

Brain-derived neurotrophic factor (BDNF) is a major factor involved in adult hippocampal neurogenesis, synaptic plasticity [64-66] and transmission [64], as well as neuronal outgrowth and extension [63]. It is secreted both pre- and postsynaptically in an activity-dependent manner in the hippocampus [65]. Extracellular BDNF binds to its endogenous receptor, tyrosine kinase receptor $\mathrm{B}$ (TrkB) [111], and this complex can be internalized. Inside the cell, BDNF modulates protein synthesis by activating proteins, like cAMP-calcium response element binding protein (CREB), ERK and phosphoinositide 3-kinase (PI3K). After both short- and long-term PA, BDNF
Table 2

The discussed growth factors and their effect on neurogenesis

\begin{tabular}{lll}
\hline $\begin{array}{l}\text { Growth } \\
\text { Factor }\end{array}$ & $\begin{array}{l}\text { Stimulates the } \ldots \\
\text { stage of neurogenesis }\end{array}$ & $\begin{array}{l}\text { Receptor }- \\
\text { cellular mechanism }\end{array}$ \\
\hline BDNF & Survival & TrkB - CREB, ERK \\
NT-3 & Survival & TrkC \\
NGF & Survival & TrkA - Akt \\
CNTF & Proliferation & CNTFR - STAT3 \\
FGF-2 & Proliferation & FGF-R - NDY1/EZH2 \\
IGF-1 & Proliferation & IGF-1R - MAPK/ERK, Akt \\
VEGF & Proliferation & Flk-1 - MAPK/ERK, Akt \\
\hline
\end{tabular}

What we know so far of the effect the mentioned growth factors have on neurogenesis and the mechanisms with which they exert this effect. $\mathrm{BDNF}=$ brain derived neurotrophic factor; $\mathrm{CNTF}=$ ciliary neurotrophic factor; CNTFR $=$ CNTF-receptor; FGF-2 $=$ fibroblast growth factor 2; Flk-1 = fetal liver kinase-1; IGF-1 = insulin-like growth factor 1; IGF-1R=IGF-1 receptor; $\mathrm{NGF}=$ neuronal growth factor; NT-3 = neurotrophin-3; TrkA/B/C = tyrosine kinase receptor $\mathrm{A} / \mathrm{B} / \mathrm{C} ; \mathrm{VEGF}=$ vascular endothelial growth factor.

is upregulated [12, 67-74, 112]. In addition, TrkB mRNA is increased upon PA [73] and this receptor is found to be expressed by NSCs [113]. PA-induced increases in acetylcholine [94, 101], through theta waves e.g., and (nor)adrenalin $[114,115]$ also trigger BDNF production [76, 101, 114, 115]. BDNF also acts as a proliferation factor in in vitro [116] and in vivo [117-119] studies. In the in vivo studies, pharmacological manipulation of BDNF resulted in BDNF-dependent proliferation in the rat hippocampus [85], while heterozygous BDNF knock-out (KO) mice had reduced proliferation [118] and BDNF infusion on the other hand, increased proliferation [119]. Moreover, many proteins activated by the BDNF-TrkB complex are known to be involved in proliferation, such as adenosine monophosphate-activated protein kinase (AMPK) and IGF-I [120], as well as classic transcription factors like CREB [66, 70], ERK [70], CAMKII [70] and Akt [67, 70]. In line with this, a loss of TrkB results in a decrease in PA-induced proliferation and a reduced size of the DG, despite normal BDNF elevations [121].

In contrast, some studies indicate that BDNF is specifically responsible for the survival of newborn neurons, not their proliferation per se. A recent study failed to produce BDNF induced proliferation. Taliaz and colleagues (2009) used RNA interference and lentiviral vectors to knock down BDNF in the DG selectively [122]. This induced depression-like behavior and reduced newborn cell survival but did not affect proliferation [122]. Secondly, proliferation of NSCs in the subventricular zone has been found to be unaltered in BDNF overexpressing mice. While the stem cells were still able to proliferate in 
response to basic FGF, BDNF addition solely induced differentiation [113].

Taken together, although hippocampal BDNF levels rise in response to $\mathrm{PA}$ and some studies suggest that BDNF is a proliferative factor, most evidence indicates that BDNF particularly stimulates the phases following proliferation.

\section{ii. $N T-3$}

Another important growth factor involved in adult proliferation and neurogenesis is neurotrophin-3 (NT3). Although PA increases levels of NT-3 and stimulates proliferation in the spinal cord [123, 124], the level of NT-3 in the hippocampus was unchanged, or possibly even decreased upon PA [37, 71, 72]. EE however, did increase hippocampal NT-3 levels [30], consistent with findings suggesting that NT-3 production is facilitated through sensory input by the lateral perforant path and is involved in cell survival rather than proliferation in the hippocampus [30, 125-127].

\section{iii. $N G F$}

Nerve Growth Factor (NGF) is one of the best known and the first identified neurotrophic factor. It binds to the tyrosine kinase receptor A (TrkA), subsequently TrkA dimerizes and activates the PI3K and Akt pathway. As explained above, running is known to activate the perforant path $[75,100]$ and to increase neurotransmitter levels [93, 102], e.g. of glutamate. The resulting neuronal depolarizations can evoke NGF production in a calcium sensitive manner [95, 126, 128]. This has been studied in rodents and an increase in hippocampal NGF has been seen in response to PA $[73,74,95,129$, 130].

NGF is a known stimulator of proliferation and differentiation for a wide variety of cells $[131,132]$. In vivo studies show that intracerebroventricular administration of NGF for six days did not affect proliferation, whereas twenty days of administration did increase newborn cell survival [133]. A study with aged rats suggest that the PA-induced increase in NGF promotes cell survival through the TrkA activated Akt pathway [95].

To conclude, NGF and its receptor levels increase in the hippocampus upon PA. Although NGF can stimulate proliferation in various conditions, other studies suggest that in the hippocampus, NGF is largely involved in Akt dependent, newborn cell survival.

\section{iv. $C N T F$}

Another growth factor that is upregulated by PA is ciliary neurotrophic factor (CNTF) which promotes neuron survival. Both $\mathrm{CNTF}$ and its receptors are in found in the CNS, mostly in astrocytes and in some neuronal populations [134, 135]. Peripheral CNTF is able to cross the BBB [136] and CNTF receptors are found in the hippocampus [135]. One of the strongest stimuli triggering CNTF production is brain injury [137, 138]. More recently, the CNTF receptor was also found to be upregulated in muscle cells upon PA [89].

Exogenously applied CNTF has been shown to increase proliferation of neurons in both the DG and subventricular zone $[134,139]$ while an experiment with a CNTR KO mouse confirmed the dependence of proliferation on CNTR. In neurosphere cell culture, the mechanism was found to be STAT3 dependent [140] as is the CNTF induction of gliogenesis [141].

Hence, CNTF could hypothetically induce hippocampal proliferation in response to PA but it is unclear to what extent this contributes to gliogenesis rather than subsequent neurogenesis and hippocampal function. Also, it remains unknown whether PA increases both peripheral and central CNTF.

$$
\text { v. } F G F-2
$$

Fibroblast growth factors (FGF) comprise a family of growth factors involved in both embryonic development [142, 143] as well as adult wound healing [143] and angiogenesis [143, 144]. FGFs regulate proliferation and differentiation in a wide variety of cells [143, 144]. FGF protein and mRNA expression increase after acute PA $[73,96,145,146]$. Studies in rodents with induced seizures suggest that an increase in brain activity is responsible for the increased expression of FGF-2 $[128,145,147]$ consistent with a study on cultured rat retinal pigment epithelial cells [148] showing that glutamate treatment specifically increased both FGF and FGF receptor (FGF-R) mRNA levels [148]. FGF, together with epidermal growth factor (EGF), are perhaps the most prominent growth factors commonly used to study proliferation in vitro [144], and proliferation of progenitor cells in the DG [142, 148]. In addition, studies using adult FGF-2 KO mice show that FGF-2 is necessary to induce proliferation following kainate induced brain damage [149]. Taken together with the PA-induced increase in hippocampal glutamate levels, it is likely that PA-induced FGF production strongly depends on glutamate signaling.

Two, not mutually exclusive, mechanisms might be responsible for the FGF-2 dependent proliferation by PA. The first mechanism is thought to involve astrocyte-mediated changes in the local environment. The increase in FGF-2 protein and mRNA levels after 
running was e.g. mainly found in astrocytes in the DG [146]. As astrocytes regulate vascular structure and play a role in energy and ion metabolism [150] for neurons throughout the brain, an increase in astrocytic FGF-2 levels might improve the vasculature and energy metabolism, which would facilitates stem cells proliferation [146].

An alternative mechanism could be astrocytic secretion of FGF-2. Astrocytes are a source of and provide both trophic factors [128] and metabolites [151] to their local environment. As astrocytes were shown to be capable of secreting FGF-2, NSCs can respond and subsequently activate specific second messenger pathways $[142,152]$ that may involve the phosphorylation of CREB, subsequently activating the NDY1/EZH2 pathway that is known to be involved in regulation of proliferation as shown by Kottakis et al. (2011) in mouse embryonic fibroblasts [144].

Thus, the PA-induced increase in hippocampal glutamate concentrations increases FGF-2 expression in astrocytes only in response to acute, not long-term, PA. FGF-2 producing astrocytes can then facilitate hippocampal stem cell proliferation by either improving the vascular system and energy metabolism in the DG, or by excreting FGF-2, or both. The astrocyteexcreted FGF-2 stimulates NSCs to proliferate via the NDY1/EZH2 pathway.

\section{vi. $I G F-1$}

A variety of both central and peripheral tissues respond to changes in peripheral glucose with the production of insulin related proteins, such as insulin-like growth factors (IGF). IGF-1 regulates metabolism and stimulates growth by regulating proliferation and differentiation of various cell types [153]. Liver [79] and muscle [78] production of IGF-1 is increased upon $\mathrm{PA}$ in response to the glucose drop. Together with AMPK it promotes energy availability and muscle recovery. Furthermore, peripheral IGF-1 can cross the $\mathrm{BBB}$, hippocampal levels of IGF-1 mRNA increase after exercise [120] and running also induced more uptake of blood IGF-I by specific groups of neurons throughout the brain $[154,155]$. IGF-1 has a role in neuroprotection and growth by inducing proliferation and increasing cell survival $[153,154,156]$. To confirm the neuroprotective effect of PA-induced IGF-1, Carro and colleagues showed that running rats displayed an IGF-1 dependent amelioration of neuron loss following brain damage [154], an amelioration that was abolished when transport of IGF-1 across the BBB was blocked using an antiserum that prevented binding of IGF-1 to its receptor (IGF-1R). This receptor, IGF-
$1 \mathrm{R}$, is also present in newly formed mature cells in the GCL [157] and when activated by central IGF-1, it phosphorylates AKT and ERK1/2, two proliferatory pathways $[105,158]$. This suggests that the neuroprotective effect of IGF-1 is mediated by activation of the IGF-1R on NSCs, which would then be expected to subsequently promote their proliferation, as confirmed using in vitro stem cells from the mouse forebrain [159]. After in vitro cloning in FGF-2 medium, the stem cells were dependent on IGF-1 to proliferate and differentiate into neurons. The ERK pathway was required to induce proliferation [160], while differentiation was found to be PI3K/Akt dependent [160]. Aberg and colleagues (2000) confirmed the in vivo proliferation following IGF-1 supplementation by means of an osmotic minipump [161] whereas rats receiving an injection of the aforementioned antiserum against the FGF-R while running showed significant decreases in proliferation [157].

Hence, we can conclude that both peripheral and central tissues contribute to the increased production of IGF-1 upon PA. Blocking IGF-1 transport over the $\mathrm{BBB}$ reduces proliferation, consistent with the idea that the most important increase likely derives from the peripheral IGF source. Peripherally produced IGF-1 is transported over the BBB via the IGF-1R, and induces proliferation in the DG through activation of the ERK, and possibly Akt, pathway.

vii. VEGF

Vascular endothelial growth factor (VEGF) is best known for its stimulatory effect on vascular cells, its role in vasculogenesis and angiogenesis but neurogenic effects have been found as well [96, 162]. It has been hypothesized that PA increases VEGF in order to repair possible tissue damage and subsequent regeneration of muscle and thereby improve the vascular system to meet the higher oxygen demands caused by PA [163, 164]. In accordance, PA increases both peripheral levels of VEGF in muscle [91, 163, 165, 166] and nerves [166], as well as central VEGF and VEGF receptor expression [96, 163]. More specifically, VEGF protein and mRNA levels were increased in the hippocampus [96] parallel to an increase of VEGF receptor 2 (fetal liver kinase-1, Flk-1) mRNA [163]. In fact, VEGF appears even necessary for exercise-induced hippocampal neurogenesis [162]. Although muscle cells secrete VEGF into the circulation [164], transport over the BBB is limited [167]. However, not all studies find a peripheral [159] or central increase in VEGF $[12,162,163]$ in response to PA, which indicates that VEGF production may depend on PA intensity. 
The increase in central VEGF after PA suggests that the neurogenic effect of VEGF, in part, depends on central VEGF, and not on (indirect) vascular changes induced by VEGF. In support, stimulation of both VEGF receptor types 1 [168] and 3 [169] in the subventricular zone causes an increase in neuronal proliferation. In addition, similar neurogenic effects can also be mediated through Flk-1 alone [170]. Moreover, the VEGF/Flk-1 complex activates the MAPK/ERK and Akt pathways to increase endothelial [106] and neuronal proliferation [171] while VEGF in vivo stimulated proliferation of neurons, astrocytes and endothelial cells in the DG. The aforementioned experiment in mouse embryonic fibroblast shows that besides FGF-2, VEGF can also activate the NDY1/EZH2 pathway [144] and VEGF thus has the potential to directly induce proliferation through multiple pathways.

However, Fabel et al. [162] indicate a more potent role of peripheral VEGF [162]. They used voluntary wheel running in mice to study effects of PA-induced increases in VEGF on neurogenesis. Using an adenoviral vector system, a peripheral blockade of VEGF was achieved, which selectively abolished the PA-induced, but not baseline, neurogenesis. This study not only demonstrates the neurogenic effect of VEGF but also highlights the importance of peripheral VEGF.

Taken together, PA increases muscle production of VEGF, which can cross the BBB. PA further stimulates VEGF and its receptor, Flk-1, in the hippocampus. VEGF further has the potential to activate the MAPK/ERK and Akt pathway through Flk-1, and so stimulate proliferation of neurons, astrocytes and endothelial cells in vivo but PA-induced neurogenesis appears to depend on peripheral VEGF that likely contributes to proliferation through changes in the vascular system.

In addition to the growth factors listed above, other factors are increased upon PA that can also induce proliferation. We will now discuss $\beta$-endorphin, angiotensin II, AMPK, adiponectin, neuropeptide Y and serotonin and their possible roles in PA-induced proliferation.

\section{b) $\boldsymbol{\beta}$-endorphin}

$\beta$-endorphins are members of the endogenous opioid system and involved in suppression of pain. They are released by the pituitary gland upon PA and during pain e.g. [78, 99]. This increase is thought to be mediated by coincident changes in glucose metabolism, or through a decrease in $\mathrm{pH}$ following cellular activity [99].
When cultured under FGF-2 rich conditions, adult hippocampal progenitor cells not only express two endogenous opioid receptors, i.e. the mu- and deltaopioid receptor (MOR and DOR, respectively), but also produce $\beta$-endorphins themselves [172]. Incubation of these cells with various MOR and DOR antagonists for 48 hours reduced the incorporation of ${ }^{3}[\mathrm{H}]$ thymidine and DNA content, indicative of a reduction in proliferative capacity. Later studies showed the effects of $\beta$-endorphin induced proliferation depend on PI3K, an activator of Akt, and MAPK/ERK1/2 pathways [172].

In vivo studies have provided evidence for the involvement of this hormone in PA-induced proliferation [173]. Wild type and $\beta$-endorphins KO mice were either housed sedentary or they ran for a short (10 days) or long (39 days) period. Whereas proliferation in the DG was similar for both genotypes in the sedentary mice, the PA-induced increase in proliferation was only observed in running wild type mice but not in the $\beta$-endorphin $\mathrm{KO}$ animals, demonstrating that $\beta$-endorphin is necessary to increase proliferation after different durations of PA. Furthermore, PA increased MOR expression in the hippocampus [174] but only after acute (5 days) and not chronic (45 days) PA and after chronic PA, MOR expression returned to baseline.

Taken together, these experiments indicated that $\beta$-endorphin modulates changes in DG proliferation during physical activity. By binding to the endogenous MOR and DOR, $\beta$-endorphin activates the MAPK/ERK1/2 pathway, and thereby induces proliferation.

\section{c) Angiotensin}

Angiotensin II (ATII) regulates blood pressure. It is produced by the peripherally but able to cross the BBB [175] where it can also target the brain vasculature.

During PA, the body produces sweat to let heat escape, this water loss can lead to dehydration. To counteract this, the kidneys release ATII, which increases vasoconstriction and increases aldosterone secretion from the kidney [78, 83].

NSCs in the rat hippocampus express the ATII type I and II receptor (AT2RI \& -RII, respectively) [176]. In vitro studies have shown that activation of AT2RII, but not AT2RI, stimulates proliferation of NSCs through a MEK, ERK and Akt pathway [176]. Moreover, AT2RII activation also increased hippocampal proliferation in vivo [177]. Following the induction of traumatic brain injury in mice, AT2RII inhibition caused a significant reduction of SGZ 
neurogenesis and reduced activation of the BDNF/ TrkB and NGF/TrkA pathways [177]. This suggested that ATII might also increase cell survival through growth factors like BDNF and NGF. However, in these studies, two conditions were compared: heat acclimation and normal temperature, and only proliferation of the heat acclimated mice was negatively affected by antagonist treatment, suggesting that AT2RII is only activated after brain injury when heat acclimation is apparent. In addition, different downstream pathways of AT2RII activation may be involved and cross-talk between both ERK and Akt cannot be excluded [178].

Taken together, the kidneys increase ATII secretion upon PA, which can induce proliferation. Whether AT2-RII is involved in the PA-induced proliferation awaits additional studies.

\section{d) AMPK, PPAR and PGC-1 $\alpha$}

Recent studies have indicated a possible role for adenosine monophosphate-activated protein kinase (AMPK) in PA-induced effects. The enzyme AMPK plays a role in energy homeostasis and increases the cellular uptake of glucose and inhibits cellular activities that consume energy and PA per se already increases AMPK [85]. Also, peripheral application of a synthetic agonist of AMPK, AICAR, increased proliferation in the DG of mice [179], suggesting AMPK might play a role in PA-induced proliferation.

The aforementioned effects of AMPK increase the overall available energy in the cell. Consistent with this, AMPK production by muscle cells is triggered by an increased cellular ratio of AMP:ATP [85, 120] and elevated specific reactive oxygen species (ROS) levels [84] following PA. In both humans and rodents, AMPK levels rise during PA $[85,86,120]$. In addition, the PA-induced increase is negatively affected with age [86].

The administration of AICAR to mice was shown to enhance water maze performance and increase both proliferation and cell survival in the hippocampus in parallel [179]. Further studies have shown that AICAR administration controls gene regulation in the hippocampus [180] and an upregulation of genes involved in neuroplasticity and neuroprotection was apparent, but also a down-regulation of genes involved in the negative regulation of neurogenesis and neurodevelopment. Among the upregulated genes was MAPK3, member of the proliferatory pathway MAPK/ERK, while a down-regulated gene was
ERRFI1, an inhibitor of proliferation [181]. However, AICAR cannot directly regulate gene expression in the hippocampus since it cannot cross the BBB and a likely explanation is that second messengers of peripherally activated AMPK can cross the BBB to regulate hippocampal gene expression.

A candidate second messenger in this respect is peroxisome proliferator-activated receptor (PPAR). PPAR is controlled by AMPK [182] and increases with PA [87]. It modulates proliferation during embryonic neurogenesis via EGF-mediated ERK activation [183]. Furthermore, PPAR modulates adult neurogenesis, although for this the involvement of ERK is not yet confirmed [184-186]. Another candidate second messenger of AMPK that might positively affect proliferation is the PPAR co-activator gamma $1 \alpha(\mathrm{PGC}-1 \alpha)$. AMPK controls PGC- $1 \alpha$ translocation [187] and in accordance, the level of PGC- $1 \alpha$ in muscle cells increases upon PA $[87,88,188]$. PGC- $1 \alpha$ combined with the aforementioned PPAR, increases production of kynurenine aminotransferase (KAT) in muscle cells of both mice and humans [88]. This enzyme converts kynurenine into kynurenine acid, which cannot cross the BBB. Agudelo and colleagues found that in mice that overexpress skeletal muscle-specific PGC-1, the amount of KAT correlated well with the reduction in kynurenine metabolites in the brain. This mouse model was resistant against stress-induced depressive behavior, a feature that has been related to changes in neurogenesis. Furthermore, the peripheral application of kynurenine resulted in anhedonic behavior in both wild type mice and in mice with a genetic deletion of PGC- $1 \alpha$.

This suggests that a change in kynurenine metabolism, through an increase in PGC- $1 \alpha$, can protect mice from stress-induced depression. The authors suggest that the change in metabolism reduces the serotonin depletion by stress and so exerts a protective effect against depression. However, both wild type and PGC- $1 \alpha$ transgenic mice showed similar levels of serotonin and another explanation is that improved cellular conditions, through e.g. a reduction of neurotoxic metabolites of kynurenine, can increase neurogenesis. Alternatively, PGC- $1 \alpha$ overexpressing mice have an increase in hippocampal levels of AMPA receptor, which can, if chronically potentiated, increase proliferation [189].

Taken together, PA increases peripheral AMPK levels. Peripheral activation of this enzyme increases proliferation in the DG. Most likely, AMPK activates second messengers that stimulate proliferatory path- 
ways. The AMPK activated PPAR and PGC- $1 \alpha$ are candidate messengers in this respect.

\section{e) Adiponectin}

Adiponectin is a metabolic hormone secreted by fat cells. It improves glucose uptake and insulin sensitivity through the adiponectin receptor 1 and 2 (AdipoR 1 $\&-2$, respectively). PA increases adiponectin secretion and recent study shows a role for adiponectin in proliferation. Also, some transport of adiponectin over the $\mathrm{BBB}$ is possible [190, 191].

Although older studies [192, 193] had found serum adiponectin levels to remain unchanged in response to PA, more recent studies [80, 194, 195] report an increase of adiponectin levels after short and long term PA. On the one hand PA directly stimulates adiponectin production, and on the other PA has the potential to slowly decrease the amount of fat cells, e.g. after prolonged PA training, which negatively regulates adiponectin. PA is also known to increase AdipoR1 and -2 in both skeletal muscle and liver tissue [80]. Moreover, both adiponectin receptors subsequently activate AMPK, PPAR- $\alpha$ and MAPK/ERK signaling proteins, all of which are involved in proliferation as well [80, 191, 192].

Adiponectin is, in lighter forms, able to cross the $\mathrm{BBB}$ and both receptors are found to be expressed within the CNS $[190,191]$. Thus, peripherally excreted adiponectin has the potential to exert effects on the brain and indeed, adiponectin, through AMPK, has been found to have neuroprotective effects after kainate induced brain injury [196] and is involved in the susceptibility for depressive-like symptoms [197]. These effects are likely mediated through an increase in neurogenesis since adiponectin receptors are present on hippocampal NCS [198] and since adiponectin can promote proliferation of these cells through activation of p38MAPK, not AMPK [198]. Yau and colleagues (2014) combined the PA increased adiponectin and the proliferatory effect of adiponectin [199] and first confirmed in vitro that adiponectin induced proliferation through AdipoR1 in hippocampal progenitor cells. Secondly, they used adiponectin deficient mice to look at neuronal and behavioral effects. Only the wild type mice had a PA-induced increase of adiponectin, phosphorylated AMPK levels in the brain and an increase in neurogenesis together with an alleviation of depressive-like symptoms. The amount of phosphorylated ERK, AKT and p38MAPK remained unchanged in all groups.
Interestingly, both the kainate study and the adiponectin deficient mice study found indications for phosphorylated AMPK dependent neurogenesis [196, 199]. AMPK is able to induce dendritic mitochondrial biogenesis, which can contribute to neurogenesis [200] or through second messengers, as explained above. However, Zhang and colleagues found adiponectin induced neurogenesis to depend on p38MAPK [198].

Taken together, PA increases both adiponectin levels, and possibly adiponectin receptor expression, in the brain. These increased levels of adiponectin can promote proliferation both in vitro and in vivo. Whether adiponectin induced proliferation is either AMPK or p38MAPK dependent, remains obscure.

\section{f) Neuropeptide $Y$}

NPY is a neurotransmitter involved in the regulation of feeding behavior, energy balance and pituitary secretion [201]. It is abundantly found in the hippocampus amongst other regions [202]. PA increases the levels of NPY in the hypothalamus [97, 203, 204]. Moreover, mRNA levels in the hippocampus increase in voluntary wheel running rats [97]. There are two aspects of PA that contribute to the increase in NPY production; the first aspect is the stress that accompanies PA in rodents [203], the second the reduction of energy storages [205].

Howel and colleagues (2005) have shown both in vivo and in vitro that NPY can induce proliferation [206]. The introduction of NPY to neuroblast cell cultures increased proliferation whereas application of the antagonist of NPY-1 receptor and the inhibitor of MEK activation of ERK1/2, abolished these in vitro effects. In vivo, the NPY-1 receptor could be linked to the proliferation, but not survival of bromodeoxyuridine (BrdU) positive cells. Thus, NPY can induce proliferation in the hippocampus via the NPY-1 receptor and activation of ERK1/2 [206].

An experiment with running rats found a correlation between the increased hippocampal NPY mRNA levels and cell proliferation [207]. Moreover, the increased levels of NPY and NPY-Y1 receptor (NPYY1R) mRNA were linked to an improvement on a forced swim task. Although a causal relation was not proven, this study confirms increases in hippocampal NPY and NPY-1R levels in response to running and suggest that NPY stimulates proliferation through NPY-1R. Taken together, there are some strong findings that NPY and its receptors are upregulated upon 
PA and that NPY stimulation can increase proliferation through ERK1/2 activation.

\section{g) Serotonin}

Serotonin, or 5-hydroxytryptamine (5-HT), is a neurotransmitter synthesized from tryptophan through tryptophan hydroxylase (TPH). Serotonin is well known for its regulation of mood and many antidepressant drugs target increase serotonin levels in the brain. Acute PA is known to increase 5-HT in the hippocampus in a time dependent manner [92, 208]. Béquet and colleagues have suggested that serotonin is upregulate in response to an increase in insulin levels, which in turn is increased by a rise in peripheral glucose levels in response to PA [92]. During PA, 5HT levels increase and after PA they slowly return to baseline, similar to the glucose dependent response.

Almost all of the 5-HT receptors subtypes are present in the hippocampus [209] and although serotonin stimulates neurogenesis both in vitro and in vivo, the precise mechanism of action, and which receptor subtypes are involved or critical, remains poorly understood. Djavadian (2004) concluded that the 5HT1a, -2a \& -2c receptor subtypes are important in this process [210] while a more recent study included 5-HT2b to the list of possible targets [211]. A study on the mechanism of acute anti-depressants points to the activation of receptor $1 \mathrm{a}$, and not 2 , that would be required for proliferation [212], but other receptors have been implicated as well, such as subtype 5-HT3,4, -6 and -7 . The last three receptors activate CREB, which could subsequently activate the NDY1/EZH2 pathway that is known to be involved in proliferation [110]. A recent review addresses the different mechanisms and involvement of these receptor subtypes in proliferation [213].

Klempin and colleagues confirmed a role for 5-HT in PA-induced proliferation [214] and showed that the PA-induced, not baseline, level of proliferation was lost in serotonin-deficient mice. Kondo and colleagues (2014) subsequently showed that an agonist for 5HTR3a increased proliferation in wild type mice, not in 5-HTr3a KO [215]. After this, they used a PA and sedentary group to investigate the effect of serotonin receptor in vivo. The $\mathrm{KO}$ mice showed a loss of PAinduced proliferation and cell survival together with a loss of the anti-depressant effect. How the 5-HTR3, that is mainly found on interneurons and some pyramidal neurons, induces cell proliferation in the DG remains elusive.

To conclude, serotonin is involved in PA-induced neurogenesis. PA-induced, but not basal levels of pro- liferation are lost in serotonin deficient or receptor KO mice. Most 5-HT subtype receptors appear to be involved but so far, only the 5-HT3 subtype has been studied in some detail in this respect.

\section{PA-INDUCED CHANGES THAT AFFECT PROLIFERATION INDIRECTLY}

Besides directly modulating (the levels of) specific bioactive compounds or mediators that affect proliferation, PA also creates or modifies conditions that can enable or facilitate proliferation indirectly, e.g. by modifying metabolism or the vasculature. Also, stress hormones are known to be elevated during PA but are at the same time well known for their own inhibitory actions on proliferation as well.

First, important indirect effects of PA comprise the multiple elements of the vascular system (Fig. 3), e.g. an increase in vascular conductance, permeability of the BBB, angiogenesis, cerebral blood flow and utilization of glucose, as reviewed elsewhere in detail $[30,216]$. These improvements facilitate the delivery of oxygen, nutrients and proteins to the brain [216] and thereby improve conditions that can in turn stimulate proliferation indirectly. The benefits of PA for the vascular system are well known and reasonably well understood in terms of mechanism $[39,91]$. Vascular conductance is e.g. increased via ATII [214] and adiponectin [215] while vasculature related compounds like ATII, VEGF and vasoactive intestinal peptide (VIP) can also increase angiogenesis after PA [22, 34, 82, 90, 91, 98, 163, 216-218]. VIP is upregulated in the hippocampus upon PA in order to reduce neuronal excitability [98].

Moreover, general changes in energy expenditure, that are to some extent regulated via FGF-2 [146], can positively affect the vascular system as well. An increase in dietary fat and leptin e.g., is associated with changes in energy expenditure regulation [219] and long term hyperleptinaemia results in leptin resistance [220], which can contribute to metabolic and cardiovascular dysfunction. PA might prevent leptin resistance by (temporarily) decreasing the levels of this hormone through an increase in adiponectin [221]. Thus, PA-induced decrease of leptin might contribute to healthy level of leptin, which maintains leptin sensitivity and so increases vascular improvement and thus conditions for proliferation, as supported by literature $[22,178]$.

Secondly, PA also facilitates proliferation through a reduction of proinflammatory cytokines (Table 1 ). 


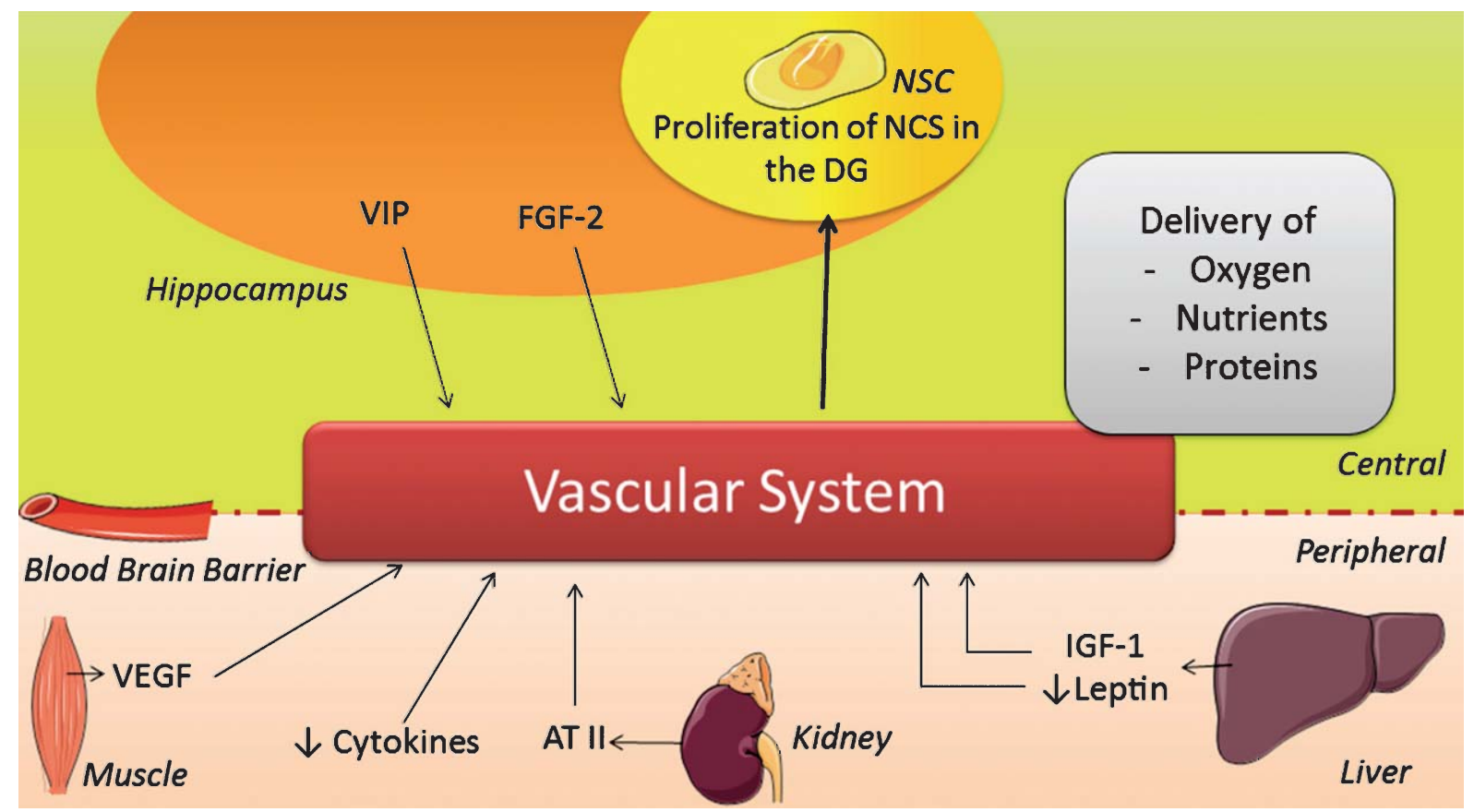

Fig. 3. Scheme illustrating the changes induced by physical activity on the vascular system. AT II = angiotensin II; FGF-2 = fibroblast growth factor 2; IGF-1 = insulin-like growth factor 1; NSC = neuronal stem cell; VEGF = vascular endothelial growth factor; VIP = vasoactive intestinal peptide.

Gibbons et al. [12] have shown that running reduced hippocampal inflammation in mice [12] and reported a reduction in the pro-inflammatory cytokine IL1- $\beta$ and microglia inflammation. These reductions were associated with an increase in neurogenesis [12]. Thus, PA reduces inflammation, which is beneficial for the overall brain health [22, 223], and can thus also indirectly facilitate neurogenesis [224].

Despite the beneficial effects of PA, a potential critical confounding factor in PA studies on rodents can be PA-induced stress [82, 225]. Whereas extensive literature shows that stress suppresses proliferation and neurogenesis in the hippocampus [3, 52, 56, 226] most likely mediated through the glucocorticoid receptor and SGK1 [33, 227, 228], such effects are context dependent and modified by several aspects. For instance, the type of stress [220], forced or voluntary, and the duration of the stress $[17,57]$, acute or chronic, modulates the effects of stress on neurogenesis as reviewed elsewhere in detail [17, 33, 229]. PA can also target cells and organs of the body through an increased generation of local ROS levels, which can damage DNA and proteins, although repair mechanisms are present too [84].

In conclusion, PA not only increases growth factors and mediators that directly induce proliferation, PA also improves conditions that facilitate neurogenesis in the brain, e.g. by improving the vascular system, modulating inflammation and through concomittant effects on the stress system.

In this review, we have discussed the many changes that occur in the periphery and brain in response to PA and contribute to the proliferation of stem cells in the DG (Fig. 2). We can conclude that at least six factors potently mediate PA-induced proliferation. Yet, there may be many more that have not been studied in this respect yet. From the other factors we mention here, their roles remains less clear or appear to resolve around cell survival instead of proliferation. Clearly, more work needs to be done here. These six factors are peripheral levels of IGF-1, VEGF and adiponectin, and centrally the serotonin, FGF- 2 and $\beta$-endorphin levels. So far, the role of age, sex and duration/intensity of exercise in regulating PA-induced adult neurogenesis has received little attention and will be discussed now.

\section{AGE RELATED CHANGES IN PA-INDUCED PROLIFERATION}

The age-related decline in cognition and neurogenesis seen in both humans and rodents [21, 230-232] has 
been proposed to be related to an age-related reduction of at least some of the mediators regulating neurogenesis. Shetty and colleagues (2005) showed that in the rat hippocampus levels of some of these factors decline with age [218]. They performed an ELISA on the hippocampus of young (4 months old), middleaged (12 months old) and aged (24 months old) rats and found FGF-2, IGF-1 and VEGF levels to be significantly lower in middle-aged and aged compared to young rats. Similarly, the basal levels of CNTF and IGF-1 were higher in younger (32 years) than older (72 years) people [159]. These factors are known to induce proliferation, a reduction could thus explain a decrease in proliferation.

Exercise may alleviate at least some of the agerelated cognitive decline possibly through an increase in neurogenesis $[12,35,38,234]$. Whether this involves PA or not, if levels of FGF-2, VEGF and IGF-1 can be increased in older subjects, this might eventually benefit cognition. However, with age, bodily responses to PA change as well. Studies have e.g. indicated a decreased production of IGF-1 by muscles and a reduction in NPY plasma levels in older subjects in response to PA $[235,236]$. In addition, with aging the perforant pathway undergoes in part, degradation [237] and consequently hippocampal acetylcholine levels decrease [238]. This might affect PA activated signaling in the DG, which could lead to a reduction of neurogenesis.

Furthermore, although the response to PA is similarly, the overall levels FGF-2, IGF-1, CNTF and VEGF are negatively affected by age [159, 233]. Together these changes might alter or reduce the beneficial effects of PA on neurogenesis with increasing age. This might explain why Van Praag and colleagues (2005) found a reduced effect of wheel running in 19 month old mice compared to 3 months old mice [35]. Both groups showed an increase in newborn neurons compared to their sedentary littermates but only the young mice had an improvement in blood vessel perimeter and surface after 1.5 months running. In addition, neurogenesis in young runners was higher than in older runners, indicating that aged rodents have a reduced response to PA with respect to both angiogenesis and neurogenesis.

Kronenberg and colleagues (2006) found a similar response to PA in 6 month, 1 year and 2 year old mice [239] and proliferation increased in all groups after 10 days running, i.e. a shorter running period than commonly used by others. Also, Kempermann (2011) states that majority of neurogenesis occurs at a young age and after adulthood, stimulatory effects on neu- rogenesis have only a modest impact [5]. This view takes in consideration many older studies [230, 231] and is consistent with a recent study in humans [232] using the ${ }^{14} \mathrm{C}$ method where a slow annual turnover of newborn cells was identified in the hippocampus with little further reduction with increasing age. From this, one might conclude that after an initial rapid drop in the postnatal and young adult period, the age-related reduction in neurogenesis is otherwise modest [35, 230, 239].

\section{SEX DIFFERENCES IN PA-INDUCED PROLIFERATION}

Given literature [11, 240, 241], sex differences are important to address in respect to PA effects on proliferation or neurogenesis. The main stimulatory factors are however upregulated to a similar extent in males and females. Even though sex differences are reported in the stress response to PA, in PA related genes and in voluntary running distance [241-243], these differences appear to have little to no effect on neurogenesis [107] and studies on both specific and more general mediators of proliferation fail to indicate a strong role for sex in the differences in PA-induced changes in neurogenesis.

\section{DIFFERENTIAL RESPONSES IN PROLIFERATION RATES BETWEEN SHORT-TERM AND LONG-TERM PA}

If PA increases proliferation and can increase learning abilities [8, 38, 48, 61, 179], one might assume this happens every time during PA. However, an increase in proliferation is only a transient phase that is part of an otherwise continuous formation of new cells and such effect are likely to modify turnover rate and should thus be seen as snapshots in time. Clearly, differences in response to either short-term or prolonged PA apply. An increase in 1 day old BrdU positive cells is seen after 24 hours of wheel access [41] which lasted up to 14 days of PA [57, 157] (see also Table 3). After this initial period, proliferation seems to return to baseline as judged from the decrease of 1 day old BrdU cells after 19 days of PA or more [57, 173, 239]. An explanation for this short-lived effect might be found in the proliferative factors discussed. FGF-2 is only upregulated for a week, after which it returns to baseline levels [73, 145, 146]. Similarly, NGF might only have an initial response to PA $[73,130]$ and the expression of the opioid receptor MOR is more 
Table 3

Different durations of exercise in relation to changes in neurogenesis (stages)

\begin{tabular}{|c|c|c|c|c|c|}
\hline $\begin{array}{l}\text { Duration } \\
\text { of PA }\end{array}$ & $\begin{array}{l}\text { Change in } \\
\text { Proliferation }\end{array}$ & $\begin{array}{l}\text { Cell } \\
\text { survival }\end{array}$ & Type of PA & Rats/Mice & Reference \\
\hline 1 day & $\uparrow(1)$ & & VWR & Female Nestin-GFP mice & [41] \\
\hline 3 days & $\uparrow(1)$ & & VWR & C57BL/6 mice & [239] \\
\hline 6 days & $\uparrow(1)$ & & VWR & $\begin{array}{l}6 \text { weeks, } 3 \text { months \& } \\
1 \text { year old C57BL/6N female mice }\end{array}$ & [214] \\
\hline 7 days & $\uparrow(7)$ & & 30 min a day & 5 weeks old Sprague-Dawley rats & {$[163]$} \\
\hline 7 days & $\uparrow(13)$ & & Restricted access to wheel & C57BL/6J mice & {$[245]$} \\
\hline 10 days & & $\uparrow(38)$ & VWR & 8 weeks female C57BL/6 mice & {$[25]$} \\
\hline 10 days & $\uparrow(1 \& \mathrm{Ki} 67)$ & & VWR & C57BL/6J mice & {$[173]$} \\
\hline 10 days & $\uparrow(1)$ & & VWR & C57BL/6 mice & [239] \\
\hline 12 days & $\uparrow(13)$ & & VWR & Female C57/BL6J mice & {$[58]$} \\
\hline 12 days & $\uparrow(13 \&$ PCNA $)$ & & VWR & $\mathrm{C} 57 / \mathrm{B} 16$ mice & [57] \\
\hline 12 days & $\uparrow(13)$ & & VWR & Female C57/BL6J mice & [26] \\
\hline 13 days & $\uparrow(13)$ & & VWR & Female C57/BL6J mice & [37] \\
\hline 2 weeks & $\uparrow(1)$ & & VWR & Wistar rats & [157] \\
\hline 19 days & $-(P C N A)$ & $\uparrow(21)$ & VWR & C57/B16 mice & [57] \\
\hline 3 weeks & & $\uparrow(21)$ & Forced (5 days a week) & Brain-damaged Sprague-Dawley rats & [70] \\
\hline 4 weeks & & $\uparrow(14)$ & VWR & Wistar rats & [157] \\
\hline 4 weeks & & $\uparrow(28)$ & VWR & Female C57/BL6J mice & [37] \\
\hline 4 weeks & & $\uparrow(29)$ & Restricted access to wheel & C57BL/6J mice & [245] \\
\hline 1 month & $\uparrow($ Ki67) & $\uparrow(28)$ & 3 times a week & CD1 mice & {$[20]$} \\
\hline 1 month & & $\uparrow(28)$ & VWR & 2 month old female C57B1/6 & [246] \\
\hline 1 month & & $-(28)$ & VWR & Female backcrossed $3 \times \mathrm{Tg}$ mice & [234] \\
\hline 1 month & & $\uparrow(60$ to 120$)$ & VWR & Female C57BL/6mice & [36] \\
\hline 32 days & $-(1)$ & & VWR & C57BL/6 mice & [239] \\
\hline 39 days & $\overline{\uparrow(\text { Ki67) })-(1)}$ & & VWR & $\mathrm{C} 57 \mathrm{BL} / 6 \mathrm{~J}$ mice & {$[173]$} \\
\hline 6 weeks & & $\uparrow(43)$ & VWR & Female C57/BL6J mice & {$[26]$} \\
\hline 43 days & & $\uparrow(31)$ & VWR & Female C57/BL6J mice & [58] \\
\hline 1.5 months & & $\uparrow(41)$ & VWR & Balb/cByJ mice & {$[12]$} \\
\hline 1.5 months & & $\uparrow(42)$ & VWR & $3 \& 19$ months old C57BL/6 mice & [35] \\
\hline 6 months & $\uparrow(1)$ & & VWR & C57BL/6 mice & [239] \\
\hline 8 months & & $\uparrow(240)$ & VWR & Female C57B1/6J & {$[38]$} \\
\hline 11 months & & $\uparrow(330)$ & VWR & Female backcrossed $3 \times \mathrm{xg}$ mice & [234] \\
\hline
\end{tabular}

The "个" depicts an increase in cell numbers and "_" depicts a lack of changes. The number between brackets relates to the number of days after the first BrdU injection before the animals were sacrificed, or the immunohistochemical marker used to asses proliferation. The type of PA was mostly voluntary wheel running (VWR). Unless mentioned otherwise, adult male rats were used (3 months or older). Surprising results are shown in bold, underlined and cursive (see the text for details).

strongly increased in short-term PA [174]. In addition, Molteni and colleagues (2002) found a reduction of the initially increased CREB after 28 days of PA in rats [73], suggesting that the body responds differently to PA after an initial first period of approximately two weeks.

The growth factor FGF-2 is a major inducer of proliferation by PA and the return to baseline of FGF-2 expression might explain the reduction of proliferation after persistent PA. However, FGF-2 expression and proliferation rate each follow a different timeline. Proliferation is reduced after two weeks, while FGF levels normalize after only one week of PA. MOR expression, also important in PA-induced proliferation, might follow this timeline more closely. NGF and CREB, although not necessarily involved in proliferation, might also contribute to conditions facilitating proliferation as would the stress system that is known to become activated after prolonged PA and associated with stereotypy [244] and prolonged forced wheel running [17]. However, not all studies find a reduction in proliferation rate after prolonged PA. Kronenberg and colleagues (2006) reported that BrdU measured proliferation was increased in rats that ran for 6 months [239]. Similar results were obtained after 1 month of wheel running [20]. Most surprisingly, one study found proliferation after 39 days PA in mice via the Ki67 marker but not via their BrdU measurement [179]. In the same study, both markers showed proliferation after 10 days of PA. Together, these studies indicate that PA increases proliferation both after short- and long-term PA, consistent with indications that PA continues to increase hippocampal volume even after 6 months of PA [44]. 


\section{CONCLUDING REMARKS}

PA triggers several peripheral and central adaptions in the body, including changes in protein, fat and glucose metabolism and hormone secretion in e.g. liver and muscles. Some of these changes can induce changes in hippocampal proliferation directly (Fig. 2) and a strong and classic response is e.g. seen from theta signaling and various neurotrophins after PA that can modulate neurotransmitter levels in the hippocampus. Of the many possible growth factors and stimuli, the six of which it has been most clearly demonstrated that they stimulate proliferation, are serotonin, FGF-2, IGF-1, VEGF, $\beta$-endorphin and adiponectin, that to some extent share considerable similarity and can e.g. be grouped based on the comparable intracellular signaling pathways they use. PA increases serotonin levels in response to a rise in insulin levels that follow PA which in turn stimulates proliferation via several receptor subtypes. PA also increases FGF2 in hippocampal astrocytes through an increase in glutamate levels. Both these centrally located factor stimulate proliferation through the NDY1/EZH2 pathway. Excretion of peripheral produced IGF-1 is also increased upon PA, this growth factor enters the brain through the IGF-1R. Here, IGF-1 exerts a prolifatory effect through the MAPK/ERK and Akt pathway. Furthermore, VEGF levels in muscles rise in response to PA, VEGF can cross the BBB and activate the same pathways as IGF-1 through Flk-1 activation. Peripheral VEGF also affects the vascular system, which facilitates conditions for proliferation. $\beta$-endorphin, increased in centrally to cope with pain accompanying PA, also activates the MAPK/ERK pathway in NSCs. Finally, adiponectin is directly upregulated in response to PA and indirectly by a decrease in fat cells. Similarly to $\beta$-endorphin, adiponectin stimulates proliferation through the AMPK or p38MAPK pathway. The other growth factors influenced by PA, i.e. BDNF, NT-3 and NGF, have a less pronounced involvement in proliferation but contribute to the further development and differentiation of these cells. PA also affects proliferation indirectly through effects on the vascular system, inflammation and the stress system.

Considering changes with age, this plays a minor role in regulating adult neurogenesis after a certain age but PA is very effective at younger ages. PA-induced proliferation is affected by age, which is thought to be partly due to deterioration of afferent inputs and decreases in IGF-1 and NPY in response to PA. Sex differences seem to have little influence on PA-induced neurogenesis.
Thus, functional neurogenesis has considerable relevance for brain plasticity, cognition and brain disorders like depression. PA is an easy accessible environmental stimulus that can increase hippocampal proliferation. Although it is not known whether PA also stimulates proliferation in human brain directly, further research is needed, beyond the bioactive compounds discussed here, into the exact mechanisms and the identification of possible additional factors that can together mimic the full potential of PA-induced changes in plasticity for the adult brain.

\section{ACKNOWLEDGMENTS}

PJL is supported by ISAO, the Hersenstichting Nederland and by Amsterdam Brain and Cognition $(\mathrm{ABC})$.

\section{REFERENCES}

[1] Dayer AG, Ford AA, Cleaver KM, Yassaee M, Cameron HA. Short-term and long-term survival of new neurons in the rat dentate gyrus. J Comp Neurol. 2003;460:563-72.

[2] Van Praag H, Schinder AF, Christie BR, Toni N, Palmer TD, Gage FH. Functional neurogenesis in the adult hippocampus. Nature. 2002;415:1030-4.

[3] Zhao C, Deng W, Gage FH. Mechanisms and functional implications of adult neurogenesis. Cell. 2008;132: 645-60.

[4] Oomen CA, Bekinschtein P, Kent BA, Saksida LM, Bussey TJ. Adult hippocampal neurogenesis and its role in cognition. Wiley Interdiscip Rev Cogn Sci. 2014;5:573-87.

[5] Kempermann G. Seven principles in the regulation of adult neurogenesis. Eur J Neurosci. 2011;33:1018-24.

[6] Amaral DG, Witter MP. The three-dimensional organization of the hippocampal formation: A review of anatomical data. Neuroscience. 1989;31:571-91.

[7] Schmidt-Hieber C, Jonas P, Bischofberger J. Enhanced synaptic plasticity in newly generated granule cells of the adult hippocampus. Nature. 2004;429:184-7.

[8] Clark PJ, Bhattacharya TK, Miller DS, Kohman RA, DeYoung EK, Rhodes JS. New neurons generated from running are broadly recruited into neuronal activation associated with three different hippocampus-involved tasks. Hippocampus. 2012;22:1860-7.

[9] Tashiro A, Makino H, Gage FH. Experience-specific functional modification of the dentate gyrus through adult neurogenesis: A critical period during an immature stage. J Neurosci. 2007;27:3252-9.

[10] Laplagne DA, Kamienkowski JE, Espósito MS, Piatti VC, Zhao C, Gage FH, et al. Similar GABAergic inputs in dentate granule cells born during embryonic and adult neurogenesis. Eur J Neurosci. 2007;25:2973-81.

[11] Chow C, Epp JR, Lieblich SE, Barha CK, Galea LAM. Sex differences in neurogenesis and activation of new neurons in response to spatial learning and memory. Psychoneuroendocrinology. 2013;38:1236-50.

[12] Gibbons TE, Pence BD, Petr G, Ossyra JM, Mach HC, Battacharya TK, et al. Voluntary wheel running, but not a diet containing (-)-epigallocatechin-3-gallate and $\beta$-alanine, 
improves learning, memory and hippocampal neurogenesis in aged mice. Behav Brain Res. 2014;272:131-40.

[13] Pan Y-W, Storm DR, Xia Z. Role of adult neurogenesis in hippocampus-dependent memory, contextual fear extinction and remote contextual memory: New insights from ERK5 MAP kinase. Neurobiol Learn Mem. 2013;105: 81-92.

[14] Erickson KI. Therapeutic effects of exercise on cognitive function. J Am Geriatr Soc. 2013;61:2038-9.

[15] Dupret D, Revest J-M, Koehl M, Ichas F, De Giorgi F, Costet $\mathrm{P}$, et al. Spatial relational memory requires hippocampal adult neurogenesis. PLoS One. 2008;3:e1959.

[16] Dupret D, Fabre A, Döbrössy MD, Panatier A, Rodríguez JJ, Lamarque S, et al. Spatial learning depends on both the addition and removal of new hippocampal neurons. PLoS Biol. 2007;5:e214.

[17] Lucassen PJ, Meerlo P, Naylor AS, Van Dam AM, Dayer AG, Fuchs E, et al. Regulation of adult neurogenesis by stress, sleep disruption, exercise and inflammation: Implications for depression and antidepressant action. Eur Neuropsychopharmacol. 2010;20:1-17.

[18] Duman RS. Depression: A case of neuronal life and death? Biol Psychiatry. 2004:56:140-5.

[19] Snyder JS, Soumier A, Brewer M, Pickel J, Cameron HA. Adult hippocampal neurogenesis buffers stress responses and depressive behaviour. Nature. 2011;476:458-61.

[20] Grégoire C-A, Bonenfant D, Le Nguyen A, Aumont A, Fernandes KJL. Untangling the influences of voluntary running, environmental complexity, social housing and stress on adult hippocampal neurogenesis. PLoS One. 2014;9: e86237.

[21] Lazarov O, Mattson MP, Peterson DA, Pimplikar SW, Van Praag $\mathrm{H}$. When neurogenesis encounters aging and disease. Trends Neurosci. 2010;33:569-79.

[22] Voelcker-Rehage C, Niemann C. Structural and functional brain changes related to different types of physical activity across the life span. Neurosci Biobehav Rev. 2013;37:226895.

[23] Tseng C-N, Gau B-S, Lou M-F. The effectiveness of exercise on improving cognitive function in older people: A systematic review. J Nurs Res. 2011;19:119-31.

[24] Wang S, Luo X, Barnes D, Sano M, Yaffe K. Physical activity and risk of cognitive impairment among oldest-old women. Am J Geriatr Psychiatry. 2013;22:1149-57.

[25] Fabel K, Wolf SA, Ehninger D, Babu H, Leal-Galicia P, Kempermann G. Additive effects of physical exercise and environmental enrichment on adult hippocampal neurogenesis in mice. Front Neurosci. 2009;3:50.

[26] Van Praag H, Kempermann G, Gage FH. Running increases cell proliferation and neurogenesis in the adult mouse dentate gyrus. Nat Neurosci. 1999;2:266-70.

[27] Wang W, Pan Y-W, Zou J, Li T, Abel GM, Palmiter RD, et al. Genetic activation of ERK5 MAP kinase enhances adult neurogenesis and extends hippocampus-dependent longterm memory. J Neurosci. 2014;34:2130-47.

[28] Klaus F, Amrein I. Running in laboratory and wild rodents: Differences in context sensitivity and plasticity of hippocampal neurogenesis. Behav Brain Res. 2012;227:363-70

[29] Bednarczyk MR, Hacker LC, Fortin-Nunez S, Aumont A, Bergeron R, Fernandes KJL. Distinct stages of adult hippocampal neurogenesis are regulated by running and the running environment. Hippocampus. 2011;21:1334-47.
[30] Olson AK, Eadie BD, Ernst C, Christie BR. Environmental enrichment and voluntary exercise massively increase neurogenesis in the adult hippocampus via dissociable pathways. Hippocampus. 2006;16:250-60.

[31] Cameron HA, Hazel TG, McKay RD. Regulation of neurogenesis by growth factors and neurotransmitters. J Neurobiol. 1998;36:287-306.

[32] Boekhoorn K, Van Dis V, Goedknegt E, Sobel A, Lucassen PJ, Hoogenraad CC. The microtubule destabilizing protein stathmin controls the transition from dividing neuronal precursors to post-mitotic neurons during adult hippocampal neurogenesis. Dev Neurobiol. 2014;74(12):1226-42.

[33] Lucassen PJ, Oomen CA, Naninck EF, Fitzsimons CP, Van Dam AM, Czeh B, Korosi A. Regulation of Adult Neurogenesis and Plasticity by (Early) Stress, Glucocorticoids, and Inflammation. Cold Spring Harb Perspect Biol. 2015;7(9):pii:a021303.

[34] Voss MW, Vivar C, Kramer AF, Van Praag H. Bridging animal and human models of exercise-induced brain plasticity. Trends Cogn Sci. 2013;17:525-44.

[35] Van Praag H, Shubert T, Zhao C, Gage FH. Exercise enhances learning and hippocampal neurogenesis in aged mice. J Neurosci. 2005;25:8680-5.

[36] Van Praag H, Christie BR, Sejnowski TJ, Gage FH. Running enhances neurogenesis, learning, and long-term potentiation in mice. Proc Natl Acad Sci USA. 1999;96:13427-31.

[37] Kobilo T, Liu Q-R, Gandhi K, Mughal M, Shaham Y, Van Praag H. Running is the neurogenic and neurotrophic stimulus in environmental enrichment. Learn Mem. 2011;18:605-9.

[38] Marlatt MW, Potter MC, Lucassen PJ, Van Praag H. Running throughout middle-age improves memory function, hippocampal neurogenesis, and BDNF levels in female C57BL/6J mice. Dev Neurobiol. 2012;72:943-52.

[39] Patten AR, Yau SY, Fontaine CJ, Meconi A, Wortman RC, Christie BR. The benefits of exercise on structural and functional plasticity in the rodent hippocampus of different disease models. Brain Plasticity, in press (2015). DOI 10.3233/BPL-150016

[40] Merkley CM, Jian C, Mosa A, Tan YF, Wojtowicz JM. Homeostatic regulation of adult hippocampal neurogenesis in aging rats: Long-term effects of early exercise. Front Neurosci. 2014;8:174.

[41] Steiner B, Zurborg S, Hörster H, Fabel K, Kempermann G. Differential $24 \mathrm{~h}$ responsiveness of Prox1-expressing precursor cells in adult hippocampal neurogenesis to physical activity, environmental enrichment, and kainic acid-induced seizures. Neuroscience. 2008;154:521-9.

[42] Van der Borght K, Kóbor-Nyakas DE, Klauke K, Eggen BJL, Nyakas C, Van der Zee EA, et al. Physical exercise leads to rapid adaptations in hippocampal vasculature: Temporal dynamics and relationship to cell proliferation and neurogenesis. Hippocampus. 2009;19:928-36.

[43] Brockett AT, LaMarca EA, Gould E. Physical exercise enhances cognitive flexibility as well as astrocytic and synaptic markers in the medial prefrontal cortex. PLoS One. 2015;10:e124859.

[44] Erickson KI, Voss MW, Prakash RS, Basak C, Szabo A, Chaddock L, et al. Exercise training increases size of hippocampus and improves memory. Proc Natl Acad Sci USA. 2011;108:3017-22.

[45] Smith JC, Nielson KA, Woodard JL, Seidenberg M, Durgerian S, Hazlett KE, et al. Physical activity reduces hip- 
pocampal atrophy in elders at genetic risk for Alzheimer's disease. Front Aging Neurosci. 2014;6:61.

[46] Smith PJ, Potter GG, McLaren ME, Blumenthal JA. Impact of aerobic exercise on neurobehavioral outcomes. Ment Health Phys Act. 2013;6:139-53.

[47] Korol DL, Gold PE, Scavuzzo CJ. Use it and boost it with physical and mental activity. Hippocampus. 2013;23:112535.

[48] Kempermann G, Fabel K, Ehninger D, Babu H, Leal-Galicia $\mathrm{P}$, Garthe A, et al. Why and how physical activity promotes experience-induced brain plasticity. Front Neurosci. 2010;4:189.

[49] Vivar C. Adult hippocampal neurogenesis, aging and neurodegenerative diseases: Possible strategies to prevent cognitive impairment. Curr Top Med Chem. 2015;15(21):2175-92.

[50] Opendak M, Gould E. Adult neurogenesis: A substrate for experience-dependent change. Trends Cogn Sci. 2015;19(3):151-61.

[51] Shors TJ, Olson RL, Bates ME, Selby EA, Alderman BL. Mental and Physical (MAP) Training: A neurogenesisinspired intervention that enhances health in humans. Neurobiol Learn Mem. 2014;115:3-9.

[52] Gage FH, Praag H Van. Neurogenesis in the adult brain. J Neurosci. 2002;22:612-3.

[53] Laplagne DA, Espósito MS, Piatti VC, Morgenstern NA, Zhao C, Van Praag H, et al. Functional convergence of neurons generated in the developing and adult hippocampus. PLoS Biol. 2006;4:e409.

[54] Van Praag H, Kempermann G, Gage FH. Neural consequences of environmental enrichment. Nat Rev Neurosci. 2000;1(3):191-8.

[55] Kempermann G, Kuhn HG, Gage FH. More hippocampal neurons in adult mice living in an enriched environment. Nature. 1997;386(6624):493-5.

[56] Saaltink D-J, Vreugdenhil E. Stress, glucocorticoid receptors, and adult neurogenesis: A balance between excitation and inhibition? Cell Mol Life Sci. 2014;71:2499-515.

[57] Snyder JS, Glover LR, Sanzone KM, Kamhi JF, Cameron HA. The effects of exercise and stress on the survival and maturation of adult-generated granule cells. Hippocampus. 2009;19:898-906.

[58] Brown J, Cooper-Kuhn CM, Kempermann G, Van Praag $\mathrm{H}$, Winkler J, Gage FH, et al. Enriched environment and physical activity stimulate hippocampal but not olfactory bulb neurogenesis. Eur J Neurosci. 2003;17:2042-6.

[59] Novak CM, Burghardt PR, Levine JA. The use of a running wheel to measure activity in rodents: Relationship to energy balance, general activity, and reward. Neurosci Biobehav Rev. 2012;36(3):1001-14.

[60] Meijer JH, Robbers Y. Wheel running in the wild. Proc Biol Sci. 2014;281:20140210.

[61] Weigmann K. Why exercise is good for your brain. EMBO Rep. 2014;15:745-8.

[62] Kannangara TS, Lucero MJ, Gil-Mohapel J, Drapala RJ, Simpson JM, Christie BR, Van Praag H. Running reduces stress and enhances cell genesis in aged mice. Neurobiol Aging. 2011;32(12):2279-86.

[63] Pérez-Domper P, Gradari S, Trejo JL. The growth factors cascade and the dendrito-/synapto-genesis versus cell survival in adult hippocampal neurogenesis: The chicken or the egg. Ageing Res Rev. 2013;12:777-85.

[64] Vivar C, Potter M, Van Praag H. All about running: Synaptic plasticity, growth factors and adult hippocampal neurogenesis. Curr Top Behav Neurosci. 2013;15:189-210.
[65] Bekinschtein P, Cammarota M, Medina JH. BDNF and memory processing. Neuropharmacology. 2014;76:677-83.

[66] Vaynman S, Ying Z, Gomez-Pinilla F. Hippocampal BDNF mediates the efficacy of exercise on synaptic plasticity and cognition. Eur J Neurosci. 2004;20:2580-90.

[67] Fang ZH, Lee CH, Seo MK, Cho H, Lee JG, Lee BJ, et al. Effect of treadmill exercise on the BDNF-mediated pathway in the hippocampus of stressed rats. Neurosci Res. 2013;76:187-94.

[68] Ferris LT, Williams JS, Shen C-L. The effect of acute exercise on serum brain-derived neurotrophic factor levels and cognitive function. Med Sci Sports Exerc. 2007;39: 728-34.

[69] Griffin É, Bechara R, Birch A, Kelly Á. Exercise enhances hippocampal-dependent learning in the rat: Evidence for a BDNF-related mechanism. Hippocampus. 2009; 19: 973-80.

[70] Ji J, Ji S, Sun R, Li K, Zhang Y, Zhang L, et al. Forced running exercise attenuates hippocampal neurogenesis impairment and the neurocognitive deficits induced by whole-brain irradiation via the BDNF-mediated pathway. Biochem Biophys Res Commun. 2014;443:646-51.

[71] Johnson R, Rhodes J, Jeffrey S, Garland T, Mitchell G. Hippocampal brain-derived neurotrophic factor but not neurotrophin-3 increases more in mice selected for increased voluntary wheel running. Neuroscience. 2003;121:1-7.

[72] Johnson RA, Mitchell GS. Exercise-induced changes in hippocampal brain-derived neurotrophic factor and neurotrophin-3: Effects of rat strain. Brain Res. 2003;983:108-14.

[73] Molteni R, Ying Z, Gomez-Pinilla F. Differential effects of acute and chronic exercise on plasticity-related genes in the rat hippocampus revealed by microarray. Eur J Neurosci. 2002;16:1107-16.

[74] Tong L, Shen H, Perreau VM, Balazs R, Cotman CW. Effects of exercise on gene-expression profile in the rat hippocampus. Neurobiol Dis. 2001;8:1046-56.

[75] Lawson VH, Bland BH. The role of the septohippocampal pathway in the regulation of hippocampal field activity and behavior: Analysis by the intraseptal microinfusion of carbachol, atropine, and procaine. Exp Neurol. 1993;120: 132-44.

[76] Berchtold NC, Kesslak JP, Cotman CW. Hippocampal brainderived neurotrophic factor gene regulation by exercise and the medial septum. J Neurosci Res. 2002;68:511-21.

[77] Slawińska U, Kasicki S. The frequency of rat's hippocampal theta rhythm is related to the speed of locomotion. Brain Res. 1998;796:327-31.

[78] Hoffman J. Physiological Aspects of Sport Training and Performance. Human Kinetics, 2nd Edition, 2014.

[79] Schwarz AJ, Brasel JA, Hintz RL, Mohan S, Cooper DM. Acute effect of brief low- and high-intensity exercise on circulating insulin-like growth factor (IGF) I, II, and IGFbinding protein- 3 and its proteolysis in young healthy men. J Clin Endocrinol Metab. 1996;81:3492-7.

[80] Passos M, Gonçalves M. Regulation of insulin sensitivity by adiponectin and its receptors in response to physical exercise. Horm Metab. 2014;46:603-8.

[81] Bouassida A, Chamari K, Zaouali M, Feki Y, Zbidi A, Tabka Z. Review on leptin and adiponectin responses and adaptations to acute and chronic exercise. Br J Sports Med. 2010;44:620-30.

[82] Essig DA, Alderson NL, Ferguson MA, Bartoli WP, Durstine JL. Delayed effects of exercise on the plasma leptin concentration. Metabolism. 2000;49:395-9. 
[83] Convertino VA, Keil LC, Greenleaf JE. Plasma volume, renin, and vasopressin responses to graded exercise after training. J Appl Physiol. 1983;54:508-14.

[84] Gomez-Cabrera M-C, Domenech E, Viña J. Moderate exercise is an antioxidant: Upregulation of antioxidant genes by training. Free Radic Biol Med. 2008;44:126-31.

[85] Steinberg G, Kemp B. AMPK in health and disease. Physiol Rev. 2009;89:1025-78.

[86] Reznick RM, Zong H, Li J, Morino K, Moore IK, Yu HJ, et al. Aging-associated reductions in AMP-activated protein kinase activity and mitochondrial biogenesis. Cell Metab. 2007;5:151-6.

[87] Russell AP, Hesselink MKC, Lo SK, Schrauwen P. Regulation of metabolic transcriptional co-activators and transcription factors with acute exercise. FASEB J. 2005;19:986-8

[88] Agudelo LZ, Femenía T, Orhan F, Porsmyr-Palmertz M, Goiny M, Martinez-Redondo V, et al. Skeletal muscle PGC-1 $\alpha 1$ modulates kynurenine metabolism and mediates resilience to stress-induced depression. Cell. 2014;159: 33-45.

[89] Hoene M, Weigert C. The stress response of the liver to physical exercise. Exerc Immunol Rev. 2010;16:163-83.

[90] Amaral SL, Papanek PE, Greene AS. Angiotensin II and VEGF are involved in angiogenesis induced by shortterm exercise training. Am J Physiol Hear Circ Physiol. 2001;281:H1163-9.

[91] Waters R, Rotevatn S, Ping L, Annex BH, Yan Z. Voluntary running induces fiber type-specific angiogenesis in mouse skeletal muscle. Am J Physiol Cell Physiol. 2004;287:13428.

[92] Béquet F, Gomez-Merino D, Berthelot M, Guezennec CY. Exercise-induced changes in brain glucose and serotonin revealed by microdialysis in rat hippocampus: Effect of glucose supplementation. Acta Physiol Scand. 2001;173:223-30.

[93] Berg DA, Belnoue L, Song H, Simon A. Neurotransmittermediated control of neurogenesis in the adult vertebrate brain. Development. 2013;140:2548-61.

[94] Itou Y, Nochi R, Kuribayashi H, Saito Y, Hisatsune T. Cholinergic activation of hippocampal neural stem cells in aged dentate gyrus. Hippocampus. 2011;21:446-59.

[95] Chae C-H, Kim H-T. Forced, moderate-intensity treadmill exercise suppresses apoptosis by increasing the level of NGF and stimulating phosphatidylinositol 3-kinase signaling in the hippocampus of induced aging rats. Neurochem Int 2009;55:208-13.

[96] Cao L, Jiao X, Zuzga DS, Liu Y, Fong DM, Young D, et al. VEGF links hippocampal activity with neurogenesis, learning and memory. Nat Genet. 2004;36:827-35.

[97] Moon H, Kim S, Yang Y. Macrophage migration inhibitory factor mediates the antidepressant actions of voluntary exercise. Proc Natl Acad Sci USA. 2012;109:13094-9.

[98] Eilam R, Davidson A, Gozes I, Segal M. Locomotor activity causes a rapid up-regulation of vasoactive intestinal peptide in the rat hippocampus. Hippocampus. 1999;9:534-41.

[99] Goldfarb AH, Jamurtas AZ. Beta-endorphin response to exercise. An update. Sport Med. 1997;24:8-16.

[100] De Bruin L, Schasfoort E, Steffens A, Korf J. Effects of stress and exercise on rat hippocampus and striatum extracellular lactate. Am J Physiol Soc. 1990;259:R773-9.

[101] Knipper M, Penha Berzaghi M, Blöchl A, Breer H, Thoenen H, Lindholm D. Positive feedback between acetylcholine and the neurotrophins nerve growth factor and brain-derived neurotrophic factor in the rat hippocampus. Eur J Neurosci. 1994;6:668-71.

[102] Nochi R, Kato T, Kaneko J, Itou Y, Kuribayashi H, Fukuda $\mathrm{S}$, et al. Involvement of metabotropic glutamate receptor 5 signaling in activity-related proliferation of adult hippocampal neural stem cells. Eur J Neurosci. 2012;36: 2273-83.

[103] Rennie K, Fréchette M, Pappas BA. The effects of neonatal forebrain cholinergic lesion on adult hippocampal neurogenesis. Brain Res. 2011;1373:79-90.

[104] Bruel-Jungerman E, Lucassen PJ, Francis F. Cholinergic influences on cortical development and adult neurogenesis. Behavioral Brain Research. 2011;221:379-88.

[105] Manning BD, Cantley LC. AKT/PKB signaling: Navigating downstream. Cell. 2007;129:1261-74.

[106] Impey S, Obrietan K, Storm DR. Making new connections. Neuron. 1999;23:11-4.

[107] Ransome MI, Hannan AJ. Impaired basal and runninginduced hippocampal neurogenesis coincides with reduced Akt signaling in adult R6/1 HD mice. Mol Cell Neurosci. 2013;54:93-107.

[108] Levy DE, Lee C. What does Stat3 do? J Clin Invest. 2002;109:1143-8.

[109] Sherry MM, Reeves A, Wu JK, Cochran BH. STAT3 is required for proliferation and maintenance of multipotency in glioblastoma stem cells. Stem Cells. 2009;27:2383-92.

[110] Nolz JC, Gomez TS, Billadeau DD. The Ezh2 methyltransferase complex: Actin up in the cytosol. Trends Cell Biol. 2005;15:514-7.

[111] Leal G, Comprido D, Duarte CB. BDNF-induced local protein synthesis and synaptic plasticity. Neuropharmacology. 2014;76:639-56.

[112] Babaei P, Damirchi A, Mehdipoor M, Tehrani BS. Long term habitual exercise is associated with lower resting level of serum BDNF. Neurosci Lett. 2014;566:304-8.

[113] Ahmed S, Reynolds BA, Weiss S. BDNF enhances the differentiation but not the survival of CNS stem cell-derived neuronal precursors. J Neurosci. 1995;15:5765-78.

[114] Akhavan MM, Emami-Abarghoie M, Safari M, SadighiMoghaddam B, Vafaei AA, Bandegi AR, et al. Serotonergic and noradrenergic lesions suppress the enhancing effect of maternal exercise during pregnancy on learning and memory in rat pups. Neuroscience. 2008;151:1173-83.

[115] Garcia C, Chen M, Garza A, Cotman C, Russo-Neustadt A. The influence of specific noradrenergic and serotonergic lesions on the expression of hippocampal brain-derived neurotrophic factor transcripts following voluntary physical activity. Neuroscience. 2003;119:721-32.

[116] Glass DJ, Nye SH, Hantzopoulos P, Macchi MJ, Squinto SP, Goldfarb M, et al. Trk13 mediates BDNF/NT-3-dependent survival and proliferation in fibroblasts lacking the low affinity NGF receptor. Cell. 1991;66:405-13.

[117] Katoh-Semba R, Asano T, Ueda H. Riluzole enhances expression of brain-derived neurotrophic factor with consequent proliferation of granule precursor cells in the rat hippocampus. FASEB J. 2002;16:1328-30.

[118] Lee J, Duan W, Mattson MP. Evidence that brain-derived neurotrophic factor is required for basal neurogenesis and mediates, in part, the enhancement of neurogenesis by dietary restriction in the hippocampus of adult mice. J Neurochem. 2002;82:1367-75.

[119] Pencea V, Bingaman KD, Wiegand SJ, Luskin MB. Infusion of brain-derived neurotrophic factor into the lateral ventricle of the adult rat leads to new neurons in the parenchyma of the 
striatum, septum, thalamus, and hypothalamus. J Neurosci. 2001;21:6706-17.

[120] Gomez-Pinilla F, Vaynman S, Ying Z. Brain-derived neurotrophic factor functions as a metabotrophin to mediate the effects of exercise on cognition. Eur $\mathrm{J}$ Neurosci. 2008;28:2278-87.

[121] Li Y, Luikart BW, Birnbaum S, Chen J, Kwon C-H, Kernie $\mathrm{SG}$, et al. TrkB regulates hippocampal neurogenesis and governs sensitivity to antidepressive treatment. Neuron. 2008;59:399-412.

[122] Taliaz D, Stall N, Dar D, Zangen A. Knockdown of brain-derived neurotrophic factor in specific brain sites precipitates behaviors associated with depression and reduces neurogenesis. Mol Psychiatry. 2009;15:80-92.

[123] Ying Z, Roy RR, Edgerton VR, Gómez-Pinilla F. Exercise restores levels of neurotrophins and synaptic plasticity following spinal cord injury. Exp Neurol. 2005;193: 411-9.

[124] Ying Z, Roy RR, Edgerton VR, Gómez-Pinilla F. Voluntary exercise increases neurotrophin-3 and its receptor TrkC in the spinal cord. Brain Res. 2003;987:93-9.

[125] Lee J, Seroogy KB, Mattson MP. Dietary restriction enhances neurotrophin expression and neurogenesis in the hippocampus of adult mice. J Neurochem. 2002;80:539-47.

[126] Poo MM. Neurotrophins as synaptic modulators. Nat Rev Neurosci. 2001;2:24-32.

[127] Shimazu K, Zhao M, Sakata K, Akbarian S, Bates B, Jaenisch R, et al. NT-3 facilitates hippocampal plasticity and learning and memory by regulating neurogenesis. Learn Mem. 2006;13:307-15.

[128] Zafra F, Lindholm D, Castrén E, Hartikka J, Thoenen H. Regulation of brain-derived neurotrophic factor and nerve growth factor mRNA in primary cultures of hippocampal neurons and astrocytes. J Neurosci. 1992;12:4793-9.

[129] Zaben MJ, Gray WP. Neuropeptides and hippocampal neurogenesis. Neuropeptides. 2013;47:431-8.

[130] Neeper SA, Gómez-Pinilla F, Choi J, Cotman CW. Physical activity increases mRNA for brain-derived neurotrophic factor and nerve growth factor in rat brain. Brain Res. 1996;726:49-56.

[131] Rende M, Brizi E, Conner J, Treves S, Censier K, Provenzano C, et al. Nerve growth factor (NGF) influences differentiation and proliferation of myogenic cells in vitro via TrKA. Int J Dev Neurosci. 2000;18:869-85.

[132] Moser KV, Reindl M, Blasig I, Humpel C. Brain capillary endothelial cells proliferate in response to NGF, express NGF receptors and secrete NGF after inflammation. Brain Res. 2004;1017:53-60.

[133] Frielingsdorf H, Simpson DR, Thal LJ, Pizzo DP. Nerve growth factor promotes survival of new neurons in the adult hippocampus. Neurobiol Dis. 2007;26:47-55.

[134] Emsley J, Hagg T. Endogenous and exogenous ciliary neurotrophic factor enhances forebrain neurogenesis in adult mice. Exp Neurol. 2003;183:298-310.

[135] Ip NY, McClain J, Barrezueta NX, Aldrich TH, Pan L, Li Y, et al. The alpha component of the CNTF receptor is required for signaling and defines potential CNTF targets in the adult and during development. Neuron. 1993;10:89-102.

[136] Poduslo J, Curran G. Permeability at the blood-brain and blood-nerve barriers of the neurotrophic factors: NGF, CNTF, NT-3, BDNF. Mol Brain Res. 1996;36:280-6.

[137] Ip NY, Wiegand SJ, Morse J, Rudge JS. Injury-induced regulation of ciliary neurotrophic factor mRNA in the adult rat brain. Eur J Neurosci. 1993;5:25-33.
[138] Rudge JS, Pasnikowski EM, Holst P, Lindsay RM. Changes in neurotrophic factor expression and receptor activation following exposure of hippocampal neuron/astrocyte cocultures to kainic acid. J Neurosci. 1995;15:6856-67.

[139] Carpenter MK, Cui X, Hu ZY, Jackson J, Sherman S, Seiger A, et al. In vitro expansion of a multipotent population of human neural progenitor cells. Exp Neurol. 1999;158:26578.

[140] Müller S, Chakrapani BPS, Schwegler H, Hofmann H-D, Kirsch M. Neurogenesis in the dentate gyrus depends on ciliary neurotrophic factor and signal transducer and activator of transcription 3 signaling. Stem Cells. 2009;27:431-41.

[141] Aberg MA, Ryttsén F, Hellgren G, Lindell K, Rosengren LE, MacLennan AJ, et al. Selective introduction of antisense oligonucleotides into single adult CNS progenitor cells using electroporation demonstrates the requirement of STAT3 activation for CNTF-induced gliogenesis.1. Mol Cell Neurosci. 2001;17:426-43.

[142] Palmer TD, Markakis EA, Willhoite AR, Safar F, Gage FH. Fibroblast growth factor-2 activates a latent neurogenic program in neural stem cells from diverse regions of the adult CNS. J Neurosci. 1999;19:8487-97.

[143] Wilkie AOM, Morriss-Kay GM, Yvonne Jones E, Heath JK. Functions of fibroblast growth factors and their receptors. Curr Biol. 1995;5:500-7.

[144] Kottakis F, Polytarchou C, Foltopoulou P, Sanidas I, Kampranis SC, Tsichlis PN. FGF-2 regulates cell proliferation, migration, and angiogenesis through an NDY1/ KDM2B-miR-101-EZH2 pathway. Mol Cell. 2011;43: 285-98.

[145] Gómez-Pinilla F, So V, Kesslak J. Spatial learning and physical activity contribute to the induction of fibroblast growth factor: Neural substrates for increased cognition associated with exercise. Neuroscience. 1998;85:53-61.

[146] Gómez-Pinilla F, Dao L, So V. Physical exercise induces FGF-2 and its mRNA in the hippocampus. Brain Res. 1997;764:1-8.

[147] Gómez-Pinilla F, Van der Wal EA, Cotman CW. Possible coordinated gene expressions for FGF receptor, FGF-5, and FGF-2 following seizures. Exp Neurol. 1995;133:164-74.

[148] Uchida N, Kiuchi Y, Miyamoto K, Uchida J, Tobe T, Tomita $\mathrm{M}$, et al. Glutamate-stimulated proliferation of rat retinal pigment epithelial cells. Eur J Pharmacol. 1998;343: 265-73.

[149] Yoshimura S, Takagi Y, Harada J, Teramoto T, Thomas SS, Waeber C, et al. FGF-2 regulation of neurogenesis in adult hippocampus after brain injury. Proc Natl Acad Sci USA. 2001;98:5874-9.

[150] Magistretti PJ, Pellerin L. Cellular mechanisms of brain energy metabolism and their relevance to functional brain imaging.Philos Trans R Soc Lond B Biol Sci. 1999;354: 1155-63.

[151] McMillian MK, Thai L, Hong J-S, O'Callaghan JP, Pennypacker KR. Brain injury in a dish: A model for reactive gliosis. Trends Neurosci. 1994;17:138-42.

[152] Palmer TD, Ray J, Gage FH. FGF-2-responsive neuronal progenitors reside in proliferative and quiescent regions of the adult rodent brain. Mol Cell Neurosci. 1995;6:474-86.

[153] Cohick WS, Clemmons DR. The insulin-like growth factors. Annu Rev Physiol. 1993;55:131-53.

[154] Carro E, Trejo JL, Busiguina S, Torres-Aleman I. Circulating insulin-like growth factor I mediates the protective effects of physical exercise against brain insults of different etiology and anatomy. J Neurosci. 2001;21:5678-84. 
[155] Carro E, Nunez A, Busiguina S, Torres-Aleman I. Circulating insulin-like growth factor I mediates effects of exercise on the brain. J Neurosci. 2000;20:2926-33.

[156] Anderson MF, Åberg MA, Nilsson M, Eriksson PS. Insulin-like growth factor-I and neurogenesis in the adult mammalian brain. Dev Brain Res. 2002;134:115-22.

[157] Trejo J, Carro E, Torres-Alemán I. Circulating insulin-like growth factor I mediates exercise-induced increases in the number of new neurons in the adult hippocampus. J Neurosci. 2001;21:1628-34.

[158] Dupont J, Pierre A, Froment P, Moreau C. The insulin-like growth factor axis in cell cycle progression. Horm Metab Res. 2003;35:740-50.

[159] Dennis RA, Przybyla B, Gurley C, Kortebein PM, Simpson $\mathrm{P}$, Sullivan DH, et al. Aging alters gene expression of growth and remodeling factors in human skeletal muscle both at rest and in response to acute resistance exercise. Physiol Genomics. 2008;32:393-400.

[160] Yuan H, Chen R, Wu L, Chen Q, Hu A, Zhang T, et al. The regulatory mechanism of neurogenesis by IGF-1 in adult mice. Mol Neurobiol. 2014;51:512-22

[161] Aberg MA, Aberg ND, Hedbäcker H, Oscarsson J, Eriksson PS. Peripheral infusion of IGF-I selectively induces neurogenesis in the adult rat hippocampus. J Neurosci. 2000;20:2896-903.

[162] Fabel K, Fabel K, Tam B, Kaufer D, Baiker A, Simmons $\mathrm{N}$, et al. VEGF is necessary for exercise-induced adult hippocampal neurogenesis. Eur J Neurosci. 2003;18:2803-12.

[163] Lou S, Liu J, Chang H, Chen P. Hippocampal neurogenesis and gene expression depend on exercise intensity in juvenile rats. Brain Res. 2008;1210:48-55.

[164] Kraus RM, Stallings HW, Yeager RC, Gavin TP. Circulating plasma VEGF response to exercise in sedentary and endurance-trained men. J Appl Physiol. 2004;96:1445-50.

[165] Schobersberger W, Hobisch-Hagen P, Fries D, Wiedermann F, Rieder-Scharinger J, Villiger B, et al. Increase in immune activation, vascular endothelial growth factor and erythropoietin after an ultramarathon run at moderate altitude. Immunobiology. 2000;201:611-20.

[166] Cheng F-C, Sheu M-L, Su H-L, Chen Y-J, Chen C-J, Chiu W-T, et al. The effect of exercise on mobilization of hematopoietic progenitor cells involved in the repair of sciatic nerve crush injury. J Neurosurg. 2013;118: 594-605.

[167] Zhu W, Mao Y, Zhao Y, Zhou L-F, Wang Y, Zhu J-H, et al. Transplantation of vascular endothelial growth factortransfected neural stem cells into the rat brain provides neuroprotection after transient focal cerebral ischemia. Neurosurgery. 2005;57:325-33; discussion 325-33.

[168] Wittko IM, Schänzer A, Kuzmichev A, Schneider FT Shibuya M, Raab S, et al. VEGFR-1 regulates adult olfactory bulb neurogenesis and migration of neural progenitors in the rostral migratory stream in vivo. J Neurosci. 2009;29:870414.

[169] Calvo C-F, Fontaine RH, Soueid J, Tammela T, Makinen T, Alfaro-Cervello C, et al. Vascular endothelial growth factor receptor 3 directly regulates murine neurogenesis. Genes Dev. 2011;25:831-44

[170] Jin K, Zhu Y, Sun Y, Mao XO, Xie L, Greenberg DA Vascular endothelial growth factor (VEGF) stimulates neurogenesis in vitro and in vivo. Proc Natl Acad Sci USA. 2002;99:11946-50.

[171] Fournier NM, Lee B, Banasr M, Elsayed M, Duman RS Vascular endothelial growth factor regulates adult hippocampal cell proliferation through MEK/ERK- and
PI3K/Akt-dependent signaling. Neuropharmacology. 2012; 63:642-52.

[172] Persson AI, Thorlin T, Bull C, Zarnegar P, Ekman R, Terenius $\mathrm{L}$, et al. $\mathrm{Mu}$ - and delta-opioid receptor antagonists decrease proliferation and increase neurogenesis in cultures of rat adult hippocampal progenitors. Eur J Neurosci. 2003; 17:1159-72.

[173] Koehl M, Meerlo P, Gonzales D, Rontal A, Turek FW, Abrous DN. Exercise-induced promotion of hippocampal cell proliferation requires beta-endorphin. FASEB J. 2008;22:2253-62.

[174] De Oliveira MSR, Da Silva Fernandes MJ, Scorza FA, Persike DS, Scorza CA, da Ponte JB, et al. Acute and chronic exercise modulates the expression of MOR opioid receptors in the hippocampal formation of rats. Brain Res Bull. 2010;83:278-83.

[175] Roncevic D. Does angiotensin II cross the blood-brain barrier? Hypertens Res. 2012;35:775.

[176] Chao J, Yang L, Buch S, Gao L. Angiotensin II increased neuronal stem cell proliferation: Role of AT2R. PLoS One. 2013;8:e63488.

[177] Umschweif G, Shabashov D, Alexandrovich AG, Trembovler V, Horowitz M, Shohami E. Neuroprotection after traumatic brain injury in heat-acclimated mice involves induced neurogenesis and activation of angiotensin receptor type 2 signaling. J Cereb Blood Flow Metab. 2014: $1-10$.

[178] Van Praag H. Exercise and the brain: Something to chew on. Trends Neurosci. 2009;32:283-90.

[179] Kobilo T, Yuan C, Van Praag H. Endurance factors improve hippocampal neurogenesis and spatial memory in mice. Learn Mem. 2011;18:103-7.

[180] Kobilo T, Guerrieri D, Zhang Y, Collica SC, Becker KG, Van Praag H. AMPK agonist AICAR improves cognition and motor coordination in young and aged mice. Learn Mem. 2014;21:119-26.

[181] Segatto O, Anastasi S, Alemà S. Regulation of epidermal growth factor receptor signalling by inducible feedback inhibitors. J Cell Sci. 2011;124:1785-93.

[182] Hardie DG. The AMP-activated protein kinase pathwaynew players upstream and downstream. J Cell Sci. 2004; 117:5479-87.

[183] Wada K, Nakajima A, Katayama K, Kudo C, Shibuya A, Kubota N, et al. Peroxisome proliferator-activated receptor- $\gamma$-mediated regulation of neural stem cell proliferation and differentiation. J Biol Chem. 2006;281: 12673-81.

[184] Cimini A, Cristiano L, Benedetti E, D'Angelo B, Cerù MP. PPARs expression in adult mouse neural stem cells: Modulation of PPARs during astroglial differentiaton of NSC. PPAR Res. 2007.

[185] Yoo DY, Kim W, Kim DW, Nam SM, Jung HY, Kim JW, et al. Cell proliferation and neuroblast differentiation in the dentate gyrus of high-fat diet-fed mice are increased after rosiglitazone treatment. J Vet Sci. 2014;15:27.

[186] Cimini A, Cerù MP. Emerging roles of peroxisome proliferator-activated receptors (PPARs) in the regulation of neural stem cells proliferation and differentiation. Stem Cell Rev. 2008

[187] Smith BK, Mukai K, Lally JS, Maher AC, Gurd BJ, Heigenhauser GJF, et al. AMP-activated protein kinase is required for exercise-induced peroxisome proliferator-activated receptor co-activator 1 translocation to subsarcolemmal mitochondria in skeletal muscle. J Physiol. 2013;591:155161 . 
[188] Arany Z. PGC-1 coactivators and skeletal muscle adaptations in health and disease. Curr Opin Genet Dev. 2008;18:426-34.

[189] Su XW, Li X-Y, Banasr M, Koo JW, Shahid M, Henry B, et al. Chronic treatment with AMPA receptor potentiator Org 26576 increases neuronal cell proliferation and survival in adult rodent hippocampus. Psychopharmacology (Berl). 2009;206:215-22.

[190] Arnoldussen IAC, Kiliaan AJ, Gustafson DR. Obesity and dementia: Adipokines interact with the brain. Eur Neuropsychopharmacol. 2014;24:1982-99.

[191] Thundyil J, Pavlovski D, Sobey CG, Arumugam TV. Adiponectin receptor signalling in the brain. Br J Pharmacol. 2012;165:313-27.

[192] Ferguson MA, White LJ, McCoy S, Kim H-W, Petty T, Wilsey J. Plasma adiponectin response to acute exercise in healthy subjects. Eur J Appl Physiol. 2004;91:324-9.

[193] Hulver MW, Zheng D, Tanner CJ, Houmard JA, Kraus WE, Slentz CA, et al. Adiponectin is not altered with exercise training despite enhanced insulin action. Am J Physiol Endocrinol Metab. 2002;283:E861-5.

[194] Abbenhardt C, McTiernan A, Alfano CM, Wener MH, Campbell KL, Duggan C, et al. Effects of individual and combined dietary weight loss and exercise interventions in postmenopausal women on adiponectin and leptin levels. J Intern Med. 2013;274:163-75.

[195] Markofski MM, Carrillo AE, Timmerman KL, Jennings K, Coen PM, Pence BD, et al. Exercise training modifies ghrelin and adiponectin concentrations and is related to inflammation in older adults. J Gerontol A Biol Sci Med Sci. 2014;69:675-81.

[196] Qiu G, Wan R, Hu J, Mattson MP, Spangler E, Liu S, et al. Adiponectin protects rat hippocampal neurons against excitotoxicity. Age (Dordr). 2011;33:155-65.

[197] Liu J, Guo M, Zhang D, Cheng S-Y, Liu M, Ding J, et al. Adiponectin is critical in determining susceptibility to depressive behaviors and has antidepressant-like activity. Proc Natl Acad Sci USA. 2012;109:12248-53. doi:10.1073/pnas.1202835109

[198] Zhang D, Guo M, Zhang W, Lu X-Y. Adiponectin stimulates proliferation of adult hippocampal neural stem/progenitor cells through activation of p38 mitogen-activated protein kinase (p38MAPK)/glycogen synthase kinase $3 \beta$ $(\mathrm{GSK}-3 \beta) / \beta$-catenin signaling cascade. J Biol Chem. 2011;286:44913-20.

[199] Yau SY, Li A, Hoo RLC, Ching YP, Christie BR, Lee TMC, et al. Physical exercise-induced hippocampal neurogenesis and antidepressant effects are mediated by the adipocyte hormone adiponectin. Proc Natl Acad Sci USA. 2014;111:15810-5.

[200] Steib K, Schäffner I, Jagasia R, Ebert B, Lie DC. Mitochondria modify exercise-induced development of stem cell-derived neurons in the adult brain. J Neurosci. 2014;34:6624-33.

[201] White JD. Neuropeptide Y: A central regulator of energy homeostasis. Regul Pept. 1993;49:93-107.

[202] Dumont Y, Martel J, Fournier A. Neuropeptide Y and neuropeptide $\mathrm{Y}$ receptor subtypes in brain and peripheral tissues. Prog Neurobiol. 1992;38:125-67.

[203] Lewis DE, Shellard L, Koeslag DG, Boer DE, McCarthy $\mathrm{HD}$, McKibbin PE, et al. Intense exercise and food restriction cause similar hypothalamic neuropeptide $\mathrm{Y}$ increases in rats. Am J Physiol Endocrinol Metab. 1993;264:E279-84.

[204] Chen J-X, Zhao X, Yue G-X, Wang Z-F. Influence of acute and chronic treadmill exercise on rat plasma lactate and brain
NPY, L-ENK, DYN A1-13. Cell Mol Neurobiol. 2007;27: $1-10$.

[205] Levine D. How does the brain create, change, and selectively override its rules of conduct? Neurodynamics Cogn Conscious. 2007:1-17.

[206] Howell OW, Doyle K, Goodman JH, Scharfman HE, Herzog H, Pringle A, et al. Neuropeptide Y stimulates neuronal precursor proliferation in the post-natal and adult dentate gyrus. J Neurochem. 2005;93:560-70.

[207] Bjørnebekk A, Mathé AA, Brené S. The antidepressant effects of running and escitalopram are associated with levels of hippocampal NPY and Y1 receptor but not cell proliferation in a rat model of depression. Hippocampus. 2010;20:820-8.

[208] Meeusen R, Thorré K, Chaouloff F, Sarre S, De Meirleir K, Ebinger G, et al. Effects of tryptophan and/or acute running on extracellular 5-HT and 5-HIAA levels in the hippocampus of food-deprived rats. Brain Res. 1996;740:245-52.

[209] Berumen LC, Rodríguez A, Miledi R, García-Alcocer G. Serotonin receptors in hippocampus. Scientific World Journal. 2012;823493.

[210] Djavadian RL. Serotonin and neurogenesis in the hippocampal dentate gyrus of adult mammals. Acta Neurobiol Exp (Wars). 2004;64:189-200.

[211] Zhang Y, Benton JL, Beltz BS. 5-HT receptors mediate lineage-dependent effects of serotonin on adult neurogenesis in Procambarus clarkii. Neural Dev. 2011;6:2.

[212] Klempin F, Babu H, De Pietri Tonelli D, Alarcon E, Fabel K, Kempermann G. Oppositional effects of serotonin receptors 5-HT1a, 2, and 2c in the regulation of adult hippocampal neurogenesis. Front Mol Neurosci. 2010;3:14.

[213] Alenina N, Klempin F. The role of serotonin in adult hippocampal neurogenesis. Behav Brain Res. 2015;277: 49-57.

[214] Klempin F, Beis D, Mosienko V, Kempermann G, Bader M, Alenina N. Serotonin is required for exercise-induced adult hippocampal neurogenesis. J Neurosci. 2013;33:8270-5.

[215] Kondo M, Nakamura Y, Ishida Y, Shimada S. The 5HT3 receptor is essential for exercise-induced hippocampal neurogenesis and antidepressant effects. Mol Psychiatry. 2014:1-10.

[216] Davenport MH, Hogan DB, Eskes GA, Longman RS, Poulin MJ. Cerebrovascular reserve: The link between fitness and cognitive function? Exerc Sport Sci Rev. 2012;40: 153-8.

[217] Schroeder A, Loh DH, Jordan MC, Roos KP, Colwell CS. Circadian regulation of cardiovascular function: A role for vasoactive intestinal peptide. Am J Physiol Heart Circ Physiol. 2011;300:H241-50.

[218] Zaben M, Sheward WJ, Shtaya A, Abbosh C, Harmar AJ, Pringle AK, et al. The neurotransmitter VIP expands the pool of symmetrically dividing postnatal dentate gyrus precursors via VPAC2 receptors or directs them toward a neuronal fate via VPAC1 receptors. Stem Cells. 2009;27:2539-51.

[219] Jéquier E. Leptin signaling, adiposity, and energy balance. Ann N Y Acad Sci. 2002;967:379-88.

[220] Ren J. Lessons from the leptin paradox in cardiac regulation-too much versus too little. J Physiol. 2005; 565:347.

[221] Calvani M, Scarfone A, Granato L, Mora EV, Nanni G, Castagneto $\mathrm{M}$, et al. Restoration of adiponectin pulsatility in severely obese subjects after weight loss. Diabetes. 2004;53:939-47.

[222] Gustafson DR. Adiposity hormones and dementia. J Neurol Sci. 2010;299:30-4. 
[223] Zigmond MJ, Smeyne RJ. Exercise: Is it a neuroprotective and if so, how does it work? Parkinsonism Relat Disord. 2014:S123-7.

[224] Ekdahl CT, Claasen J-H, Bonde S, Kokaia Z, Lindvall O. Inflammation is detrimental for neurogenesis in adult brain. Proc Natl Acad Sci USA. 2003;100:13632-7.

[225] Brown DA, Johnson MS, Armstrong CJ, Lynch JM, Caruso NM, Ehlers LB, et al. Short-term treadmill running in the rat: What kind of stressor is it? J Appl Physiol. 2007;103: 1979-85.

[226] Anacker C, Cattaneo A, Musaelyan K, Zunszain PA, Horowitz M, Molteni R, et al. Role for the kinase SGK1 in stress, depression, and glucocorticoid effects on hippocampal neurogenesis. Proc Natl Acad Sci USA. 2013;110: 8708-13.

[227] Oomen CA, Mayer JL, De Kloet ER, Joels M, Lucassen PJ. Brief treatment with the glucocorticoid receptor antagonist mifepristone normalizes the reduction in neurogenesis after chronic stress. Eur J Neurosci. 2007;26:3395-401.

[228] Fitzsimons CP, Van Hooijdonk LWA, Schouten M, Zalachoras I, Brinks V, Zheng T, et al. Knockdown of the glucocorticoid receptor alters functional integration of newborn neurons in the adult hippocampus and impairs fearmotivated behavior. Mol Psychiatry. 2013;18:993-1005.

[229] Egeland M, Zunszain PA, Pariante CM. Molecular mechanisms in the regulation of adult neurogenesis during stress. Nat Rev Neurosci. 2015;16:189-200.

[230] Heine VM, Maslam S, Joëls M, Lucassen PJ. Prominent decline of newborn cell proliferation, differentiation, and apoptosis in the aging dentate gyrus, in absence of an age-related hypothalamus-pituitary-adrenal axis activation. Neurobiol Aging. 2004;25:361-75.

[231] Kuhn HG, Dickinson-Anson H, Gage FH. Neurogenesis in the Dentate Gyrus of the Adult Decrease of Neurona Progenitor Proliferation Rat: Age-related decrease of neuronal progenitor proliferation. J Neurosi. 1996;16: 2027-33.

[232] Spalding KL, Bergmann O, Alkass K, Bernard S, Salehpour M, Huttner HB, et al. Dynamics of hippocampal neurogenesis in adult humans. Cell. 2013;153:1219-27.

[233] Shetty AK, Hattiangady B, Shetty GA. Stem/progenitor cell proliferation factors FGF-2, IGF-1, and VEGF exhibit early decline during the course of aging in the hippocampus: Role of astrocytes. Glia. 2005;51:173-86.

[234] Marlatt M, Potter M, Bayer T, Van Praag H, Lucassen PJ. Prolonged running, not fluoxetine treatment, increases neu- rogenesis, but does not alter neuropathology, in the $3 \times \mathrm{Tg}$ mouse model of Alzheimer's disease. Curr Top Behav Neurosci. 2013;15:313-40.

[235] Jensen EW, Espersen K, Kanstrup IL, Christensen NJ. Agerelated changes of exercise-induced plasma catecholamines and neuropeptide $\mathrm{Y}$ responses in normal human subjects. Acta Physiol Scand. 1992;144:129-33.

[236] Jensen EW, Espersen K, Kanstrup IL, Christensen NJ. Exercise-induced changes in plasma catecholamines and neuropeptide Y: Relation to age and sampling times. J Appl Physiol. 1994;76:1269-73.

[237] Yassa MA, Muftuler LT, Stark CEL. Ultrahigh-resolution microstructural diffusion tensor imaging reveals perforant path degradation in aged humans in vivo. Proc Natl Acad Sci USA. 2010;107:12687-91.

[238] Kehr J, Yoshitake T, Wang F, Wynick D, Holmberg K, Lendahl U, et al. Microdialysis in freely moving mice: Determination of acetylcholine, serotonin and noradrenaline release in galanin transgenic mice. J Neurosci Methods. 2001;109:71-80.

[239] Kronenberg G, Bick-Sander A, Bunk E, Wolf C, Ehninger D, Kempermann G. Physical exercise prevents age-related decline in precursor cell activity in the mouse dentate gyrus. Neurobiol Aging. 2006;27:1505-13.

[240] Rummel J, Epp JR, Galea LAM. Estradiol does not influence strategy choice but place strategy choice is associated with increased cell proliferation in the hippocampus of female rats. Horm Behav. 2010;58:582-90.

[241] Westenbroek C, Den Boer JA, Veenhuis M, Ter Horst GJ. Chronic stress and social housing differentially affect neurogenesis in male and female rats. Brain Res Bull. 2004;64:303-8.

[242] Wolfarth B. Genes and endurance performance. Genet Mol Asp Sport Perform. 2011;151-8.

[243] Lightfoot JT. Sex hormones' regulation of rodent physical activity: A review. Int J Biol Sci. 2008;4:126-32.

[244] Sherwin CM. Voluntary wheel running: A review and novel interpretation. Anim Behav. 1998;56:11-27.

[245] Holmes MM, Galea LAM, Mistlberger RE, Kempermann G. Adult hippocampal neurogenesis and voluntary running activity: Circadian and dose-dependent effects. J Neurosci Res. 2004;76:216-22.

[246] Marlatt MW, Lucassen PJ, Van Praag H. Comparison of neurogenic effects of fluoxetine, duloxetine and running in mice. Brain Res. 2010;1341:93-9. 